\title{
IL-15 complexes induce NK- and T-cell responses independent of type I IFN signaling during rhinovirus infection
}

\author{
A Jayaraman $^{1,2,3}$, DJ Jackson ${ }^{1,2,3,4}$, SD Message ${ }^{1,7}$, RM Pearson ${ }^{1,2,3}$, J Aniscenko ${ }^{1,2,3}$,

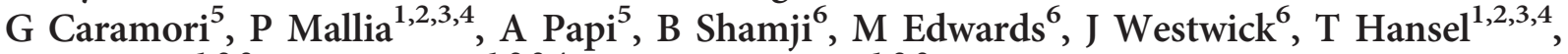 \\ LA Stanciu $^{1,2,3}$, SL Johnston ${ }^{1,2,3,4}$ and NW Bartlett ${ }^{1,2,3}$
}

Rhinoviruses are among the most common viruses to infect man, causing a range of serious respiratory diseases including exacerbations of asthma and COPD. Type I IFN and IL-15 are thought to be required for antiviral immunity; however, their function during rhinovirus infection in vivo is undefined. In RV-infected human volunteers, IL-15 protein expression in fluid from the nasal mucosa and in bronchial biopsies was increased. In mice, RV induced type I IFN-dependent expressions of IL-15 and IL-15R $\alpha$, which in turn were required for NK- and CD8 ${ }^{+}$T-cell responses. Treatment with IL-15-IL-15R $\alpha$ complexes (IL-15c) boosted RV-induced expression of IL-15, IL-15R $\alpha$, IFN- $\gamma$, CXCL9, and CXCL10 followed by recruitment of activated, IFN- $\gamma$-expressing NK, $\mathrm{CD}^{+}$, and $\mathrm{CD} 4^{+} \mathrm{T}$ cells. Treating infected IFNAR1 ${ }^{-1-}$ mice with IL-15c similarly increased IL-15, IL-15R $\alpha$, IFN- $\gamma$, and CXCL9 (but not CXCL10) expression also followed by NK-, CD8 ${ }^{+}$-, and CD4 ${ }^{+}$-T-cell recruitment and activation. We have demonstrated that type I IFN-induced IFN- $\gamma$ and cellular immunity to RV was mediated by IL-15 and IL-15R $\alpha$. Importantly, we also show that IL-15 could be induced via a type I IFN-independent mechanism by IL15 complex treatment, which in turn was sufficient to drive IFN- $\gamma$ expression and lymphocyte responses.

\section{INTRODUCTION}

Infection with human rhinoviruses (RV) is the most common viral infection afflicting mankind. Although the nasal epithelium is the primary site of replication manifesting as the common cold, RV can also be detected in the lower airways ${ }^{1,2}$ where it can cause severe and life-threatening exacerbations in patients with asthma, chronic obstructive pulmonary disease (COPD), and pneumonia. ${ }^{3,4}$ Collectively, these diseases are responsible for significant morbidity and mortality and enormous health-care costs. ${ }^{5}$

Despite their significant involvement in respiratory diseases, surprisingly little is known about the role of cellular immune responses in RV pathogenesis. The involvement of natural killer (NK) cells and $\mathrm{T}$ cells during $\mathrm{RV}$ infection has been inferred from numerous studies demonstrating robust induction of lymphocyte-recruiting chemokines such as
CXCL10 during infection. ${ }^{6}$ Experimental infection studies in man have demonstrated infiltrating lymphocytes in nasal mucosa and bronchial biopsies associated with blood lymphopenia. ${ }^{7}$ Characterization of blood leukocyte responses identified a significant reduction in $\mathrm{CD} 4^{+} \mathrm{T}$ cells, suggesting that these are preferentially recruited to the site of $\mathrm{RV}$ infection. ${ }^{8}$ More recently, mouse infection models have been developed allowing more detailed analyses of immune responses to RV. These have begun to confirm that RV can induce a range of lymphocyte-recruiting mediators associated with infiltration of NK cells and T cells to the lung. ${ }^{9,10}$

Interleukin-15 (IL-15) is a type I interferon (IFN)-induced cytokine that exerts antiviral effects by activation of NK cells and CD8 ${ }^{+}$T cells. ${ }^{11,12}$ IL-15 shares the IL-2R $\beta$ - and common $\gamma$-chains of the IL-2 receptor, ${ }^{13,14}$ but also binds its specific IL$15 \mathrm{R} \alpha$-chain with much greater affinity. ${ }^{15}$ Signaling occurs via a

\footnotetext{
${ }^{1}$ Airway Disease Infection Section, National Heart and Lung Institute, Imperial College London, London, UK. ${ }^{2} \mathrm{MRC}$ and Asthma UK Centre in Allergic Mechanisms of Asthma, London, UK. ${ }^{3}$ Centre for Respiratory Infections, Imperial College London, London, UK. Imperial College Healthcare National Health Service Trust, London, UK. ${ }^{5}$ Sezione di Malattie dell'Apparato Respiratorio, Centro per lo Studio delle Malattie Infiammatorie Croniche delle Vie Aeree e Patologie Fumo Correlate dell'Apparato Respiratorio (CEMICEF), University of Ferrara, Ferrara, Italy and ${ }^{6}$ Novartis Institute for Biomedical Research, Horsham, UK. Correspondence: NW Bartlett (n.bartlett@ic.ac.uk)

${ }^{7}$ Current address: Department of Thoracic Medicine, Gloucestershire Royal Hospital, Gloucester, UK.
} 


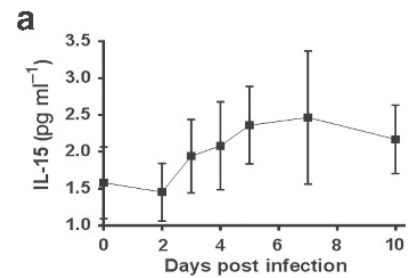

C

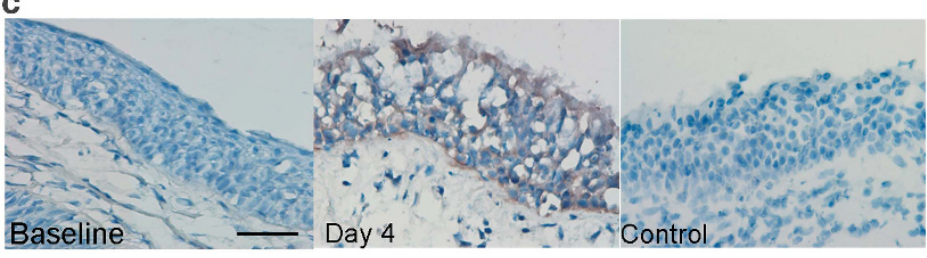

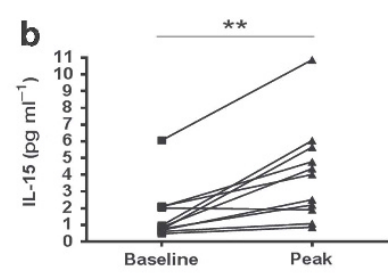

d

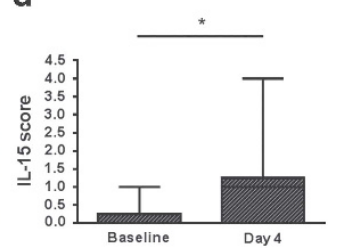

Figure 1 Experimental human RV infection induced IL-15 and associated Th1 and inflammatory mediators. Healthy volunteers were infected with RV16 and levels of soluble mediators in the nasal mucosal fluid were measured by MSD platform and IL-15 in the epithelium of bronchial biopsies measured by IHC. (a) Levels of IL-15 protein in the nasal mucosa during infection. (b) Baseline and peak infection levels of IL-15. (c) Images of representative IHC staining for IL-15 protein in human bronchial biopsies at 14 days before infection (baseline), 4 days post infection with RV and normal mouse serum staining control. (d) IHC staining score for IL-15 in bronchial biopsies. Bar $=50 \mu \mathrm{m}$. IL-15 data are presented as mean \pm s.e.m., baseline compared with infection peak data were analyzed by Mann-Whitney test. ${ }^{* \star} P<0.01$ and ${ }^{\star} P<0.05$ as indicated. Differences were considered significant for all statistical tests at $P<0.05$. All reported $P$-values are two-sided. IHC, immunohistochemistry; IL-15, interleukin-15; MSD, Meso-Scale Discovery; NS, not significant; RV, rhinovirus.

unique trans-presentation mechanism involving IL-15 expression by macrophages, dendritic cells (DCs), and epithelial cells where it is bound and stabilised by IL- $15 \mathrm{R} \alpha$ and transported to the cell surface membrane for presentation to adjacent neighboring cells in trans. ${ }^{16,17}$ During infection, IL-15 is critical for the activation, recruitment, and expansion of NK cells and $\mathrm{CD}^{+} \mathrm{T}$ cells. NK cells are innate effector lymphocytes that can directly eliminate virally infected cells through the production of cytolytic enzymes such as granzymes and produce cytokines such as IFN- $\gamma$ that regulate adaptive immune responses. ${ }^{18,19}$ Direct type I IFN signaling is reported important for regulating NK-cell functions during viral infections. ${ }^{20-22}$ NK-cell development and homeostasis is also dependent on IL-15 signaling as illustrated by the severe deficiency of NK cells in IL-15 ${ }^{-1-}$ and IL-15R $\alpha^{-1-}$ mice..$^{23,24}$ IL-15 and NK cells are also important for regulating adaptive $\mathrm{T}$-cell responses during respiratory infections, with depletion of NK cells causing impaired CD8 ${ }^{+}$T-cell responses against influenza and $M$. tuberculosis. ${ }^{25,26}$

We have previously used in vitro RV infection models involving bronchial epithelial cells and bronchoalveolar lavage (BAL) macrophages to identify deficient expression of type I IFN in asthma and $\mathrm{COPD}^{27,28}$ and IL-15 in asthma, ${ }^{29}$ identifying a potentially important link between IFN and IL-15 in the pathogenesis of RV-induced disease. To investigate the effect of loss of type I IFN-mediated responses in vivo, we used a mouse RV infection model observing severely impaired NK-cell and T-cell responses in type I IFN receptor knockout (IFNAR $^{-1-}$ ) mice. Clearly type I IFN was critical for NK-cell responses to $\mathrm{RV}$; however, the role of IL-15 was not studied. ${ }^{10}$

In the present study, we investigated the interaction between type I IFN-mediated responses, IL-15, and cellular immunity following RV infection in vivo in man and mouse. We found that RV infection induced IL-15 protein production in nasal and bronchial mucosa of healthy human subjects. We have provided novel in vivo data showing that RV-induced IL-15/IL$15 \mathrm{R} \alpha$ expression was mediated by type I IFN, which in turn was required for early expression of IFN- $\gamma$ and recruitment of activated, IFN- $\gamma$-expressing NK cells and T cells. We have further demonstrated that exogenous delivery to the airways of biologically active IL-15 complexed with IL-15R $\alpha$ (IL-15c) during RV infection in both wild-type (wt) and IFNAR1 ${ }^{-1-}$ mice boosted early lung expression of IFN- $\gamma$ and the lymphocyte-recruiting chemokine CXCL9/MIG (monokine induced by gamma interferon) followed by lymphocyte recruitment.

\section{RESULTS}

RV infection-induced IL-15 in nasal and bronchial mucosa was associated with Th1 immunity

We employed a human experimental RV infection model recruiting healthy volunteers to determine whether $\mathrm{RV}$ infection induced IL-15 expression in vivo. In a group of 11 human subjects, we repeatedly sampled the nasal mucosal fluid before infection and up to 10 days after infection (Figure 1a). When baseline levels were compared with the peak infection levels for each subject, we observed a significant increase in IL15 protein (Figure 1b). Viral load in nasal lavage was determined by PCR analysis of viral RNA levels. Although viral RNA- and IL-15 protein-levels typically peaked between day 2 and day 6 post infection, no statistically significant correlation for peak viral load with IL-15 was observed (data not shown).The lack of a clear relationship between peak IL-15 expression and viral load was likely due to the small number of subjects (11), which meant the study was not powered to quantify the dynamic interaction between IL-15 and viral load.

In a separate study also involving 11 healthy volunteers experimentally infected with the same RV-16 inoculum, ${ }^{30}$ we used immunohistochemistry (IHC) to detect IL-15 protein expression in the lower airways (bronchial biopsies) at baseline 
( 2 weeks before infection) and 4 days after infection. IL-15 positivity was apparent on the apical surface of the epithelium and in cells directly below the epithelium (Figure 1d) and was significantly increased compared with uninfected subjects (Figure 1e).

\section{IL-15 and IL-15R $\alpha$ expression during RV infection}

We used a mouse RV infection model to analyze Il15 and Il15ro mRNA expression by BAL cells (Figure 2a) and lung tissue (Figure 2b), observing significantly increased levels compared with baseline and UV-inactivated RV-1B (UV-RV-1B)-dosed mice. Expression of mRNA for both molecules peaked at 1 day post infection (p.i.) returning to baseline levels by 4 days p.i. (Figure 2a and b). Upregulated expression of IL-15 and IL-15R $\alpha$ proteins (measured as soluble IL-15-IL-15R $\alpha$ complexes) in lung tissue similarly peaked at 1 day p.i. (Figure 2c). Further analysis of lung IL-15 protein by IHC revealed increased expression by bronchial epithelial cells and subepithelial DC-like cells in RVinfected mouse lungs (Figure 2d), which when scored was significantly higher than IL-15 expression in uninfected mice and mice dosed with UV-RV-1B (Figure 2e). A small increase in IL-15 protein following UV-inactivated virus was detected by IHC but was not apparent in lung homogenate using ELISA. This was likely due to differences in sensitivity of the two assays. The peak of IL-15 and IL-15R $\alpha$ expressions coincided with peak viral loads in the lung at 1 day p.i., which remained elevated at 2 days p.i. and declined thereafter (Figure 2e).

\section{Type I IFN receptor is required for IL-15 and IL-15R $\alpha$ expression}

Type I IFNs are reported to induce expression of IL-15 by macrophages, DCs, and epithelial cells, ${ }^{11}$ and RV-induced expression of IFN- $\alpha$ and IFN- $\beta$ in BALB/c mice (Supplementary Figure S1 online) was associated with expression of IL-15 and IL- $15 R \alpha$ at $24 \mathrm{~h}$ p.i. We have previously shown that type I IFN receptor knockout (IFNAR $1^{-I^{-}}$) mice have deficient type I and type III IFN production and NK-cell responses during RV infection; however, IL-15 expression was not assessed. ${ }^{10}$ Therefore, we used these mice to determine whether type I IFN signaling was required for IL-15 expression during RV infection. Significantly attenuated $I l 15$ and Il15r $\alpha$ mRNA expression was observed in IFNAR1 ${ }^{-1-}$ mice compared with strain-matched wt mice (Figure 3a) with trends for reduction in IL-15 and IL$15-\mathrm{IL}-15 \mathrm{R} \alpha$ protein complexes in lung tissue (Figure $3 \mathbf{b}$ ).

\section{IL-15 is critical for the NK-cell and CD8 ${ }^{+} \mathrm{T}^{-}$-cell responses during RV infection}

Next, we performed a time course analysis of NK-cell responses in the BAL and lung observing peak NK-cell accumulation at 2 days p.i., and peak numbers of NK cells expressing CD69, IFN$\gamma$, and granzyme B were also detected at this time point (Supplementary Figure S2). NK-cell numbers declined to baseline by day 4 and day 7 in the BAL and lung, respectively, with levels of IFN- $\gamma^{+} \mathrm{NK}$ cells remaining significantly elevated over controls at day 4 p.i. in the lung. UV-inactivated RV failed to induce NK-cell responses.
IL-15 ${ }^{-/-}$and IL-15R $\alpha^{-/-}$mice have a severe deficiency of NK cells. One option available to study IL-15-mediated NK-cell responses during RV infection was to transiently block IL-15 in the lung. We investigated the dependence of RV-induced NK cell responses on IL-15 by i.n. administration of an IL-15 neutralizing antibody (M96) at the time of infection in order to transiently block virus-induced lung IL-15 activity. To ensure the antibody did not greatly affect basal lymphocyte levels systemically, we assessed the lung and spleen in uninfected mice observing no significant change in total leukocyte cell numbers or percentage of $\mathrm{CD} 4{ }^{+}$and $\mathrm{CD} 8^{+} \mathrm{T}$ cells, indicating that cells other than NK cells were not affected by antibody treatment in the absence of infection. In the spleen, the percentage of NK cells declined approximately $30 \%$ at $48 \mathrm{~h}$, and in the lungs approximately $50 \%$ at $48 \mathrm{~h}$ after antibody treatment (Supplementary Figure S3).

Although antibody treatment modestly affected NK-cell baseline levels by $48 \mathrm{~h}$ post treatment, the administration of antibody at the time of infection, when NK-cell numbers were normal, permitted investigation into the role of RV-induced IL15 on the accumulation and activation of NK cells. The presence of IL-15-neutralizing antibody at the time of infection resulted in a $>90 \%$ and approximately $75 \%$ reduction in total NK-cell numbers in BAL and lung tissue, respectively, by $48 \mathrm{~h}$ after infection (Figure 4a). Similarly CD $69^{+}$, IFN $-\gamma^{+}$, or granzyme $\mathrm{B}^{+} \mathrm{NK}$ cells failed to accumulate with IL-15 neutralisation, further evidence of a critical role in pulmonary NK-cell responses during RV infection (Figure $\mathbf{4 b} \mathbf{b}-\mathbf{d}$ ). In association with these deficient NK-cell responses, Ifn $\gamma$ gene expression in the lung was also significantly suppressed (Figure 4e).

As $\mathrm{CD} 8^{+} \mathrm{T}$-cell responses during RV infection have not been studied in vivo, we analyzed these cells and assessed the role of IL-15 using M96. We found that CD8 ${ }^{+} \mathrm{T}$-cell responses were also impaired in RV-M96-treated mice compared with controls (Figure 5a), analyzed at $48 \mathrm{~h}$ p.i., which was previously observed to be the peak of the $\mathrm{CD}^{+}{ }^{+} \mathrm{T}$-cell response to $\mathrm{RV}$ infection in mice (data not shown). RV-M96-treated mice demonstrated significantly reduced numbers of total $\mathrm{CD} 8^{+} \mathrm{T}$ cells, $\mathrm{CD} 69^{+} \mathrm{CD} 8^{+} \mathrm{T}$ cells, and IFN $-\gamma^{+} \mathrm{CD} 8^{+} \mathrm{T}$ cells compared with control-infected mice in the BAL. The same trend was observed in lung tissue, but statistical significance was only reached for reduced numbers of total $\mathrm{CD} 8{ }^{+} \mathrm{T}$ cells between RV-M96- and RV-PBS-treated mice (Figure 5a).

To further investigate the role of IL-15 during RV infection, we studied IL-15R $\alpha$ knockout (IL-15R $\alpha^{-/-}$) mice, which have a severe deficiency of NK cells. We confirmed this and that RV infection could not induce NK-cell responses in these mice (Supplementary Figure S4). We next assessed total, $\mathrm{CD} 69^{+}$, and IFN- $\gamma^{+} \mathrm{CD}^{+}{ }^{+}$T numbers in the airways and lung tissue during $\mathrm{RV}$ infection, observing that $\mathrm{CD} 8{ }^{+} \mathrm{T}$-cell responses were also severely impaired in IL-15R $\alpha^{-1-}$ mice (Figure 5b) as was IFN- $\gamma$ expression (Figure 5c). Transiently blocking IL15 using M96 did not have a significant impact on the level of RV RNA in the lungs (Figure 5d). In contrast, by $24 \mathrm{~h}$ p.i. we did observe significantly increased RV RNA in the lungs of IL$15 \mathrm{R} \alpha^{-1-}$ mice when compared with infected wt controls 

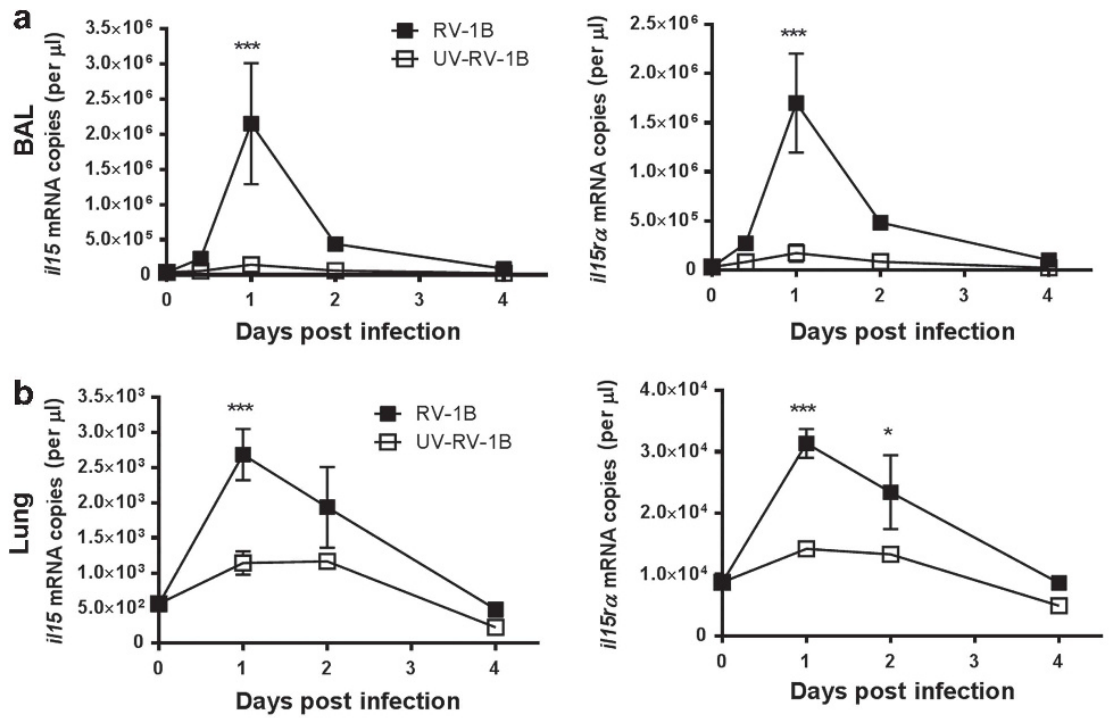

C
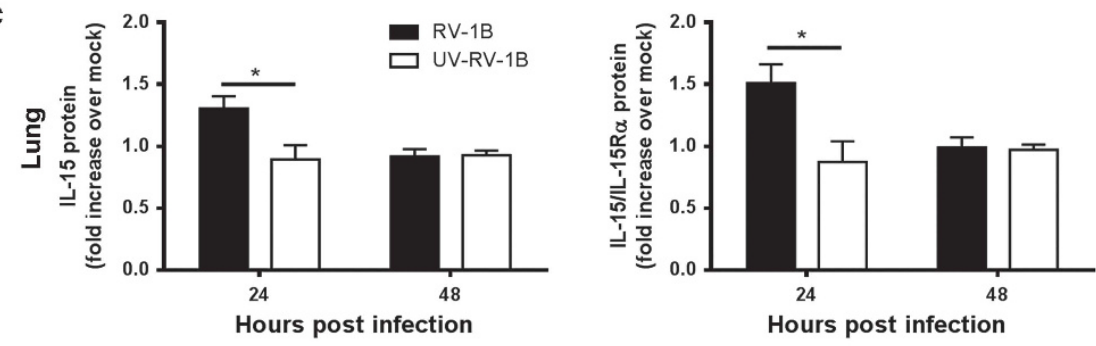

d

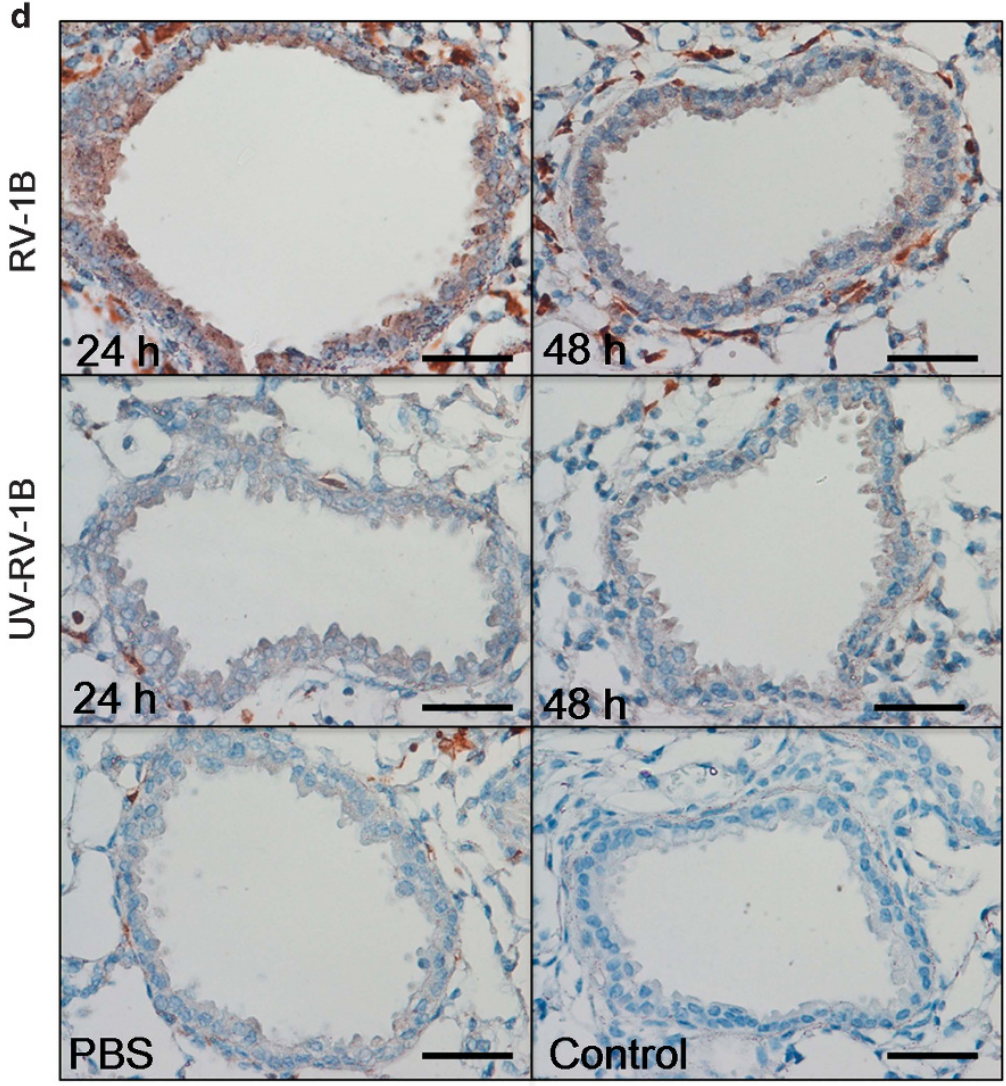

e
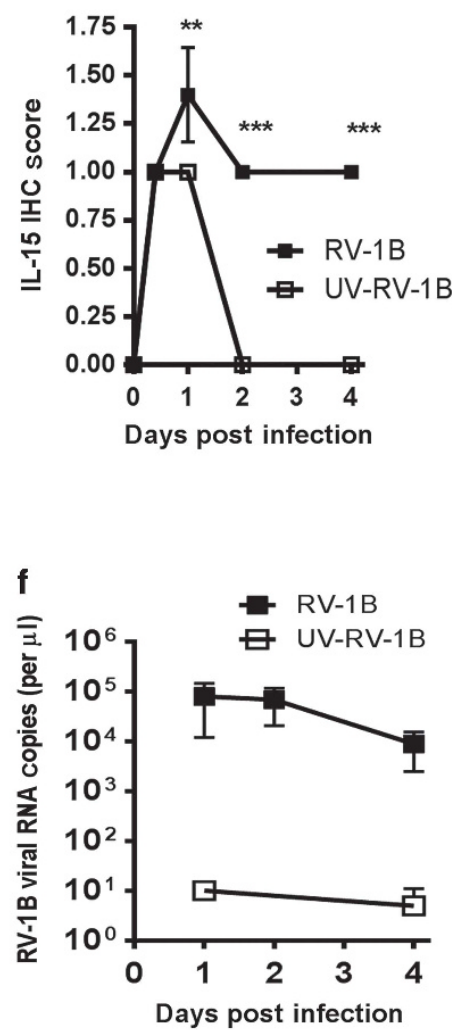
(Figure 5e). We noted that viral load was higher in B6.129 mice (control for IL-15R $\alpha^{-1-}$ mice) compared with BALB/c mice used in the anti-IL-15 antibody-blocking studies. Therefore, differences in mouse strain susceptibility to viral infection may have also contributed to the greater apparent effect of IL-15 receptor deficiency on lung viral load.

\section{Exogenous IL-15-IL-15 receptor complexes do not require} type I IFN to induce IFN- $\gamma$ and lymphocyte recruitment

$\mathrm{RV}$ infection studies with models of IL-15 deficiency revealed that IL-15 was required for IFN- $\gamma$ expression and lymphocyte activation and recruitment (Figures 4 and 5). We hypothesized that supplementing bioactive IL-15 complexed to IL-15R $\alpha$ (IL15c) should boost these responses. The role of type I IFN in this process was also investigated using IFNAR $1^{-/-}$mice. We have previously reported that IFNAR $1^{-/}$mice fail to recruit and activate NK cells in response to RV infection, ${ }^{10}$ which was confirmed for this study (Supplementary Figure S5). IL-15c treatment alone (in the absence of infection) did not affect baseline lung $\mathrm{NK}$ cell or $\mathrm{CD}^{+}{ }^{+}$and $\mathrm{CD} 8{ }^{+}$T-cell numbers or activation status in either wt or IFNAR $1^{-/-}$mice. In RVinfected wt mice, IL-15c treatment significantly boosted NK-cell responses over that induced by infection alone in the BAL (Figure 6a) and lung (Figure 6b) as indicated by increased total, $\mathrm{CD} 9^{+}, \mathrm{IFN}-\gamma^{+}$, and granzyme $\mathrm{B}^{+} \mathrm{NK}$-cell numbers. Furthermore, administering IL-15c to IFNAR $1^{-/-}$ mice completely restored $\mathrm{NK}$-cell responses to $\mathrm{RV}$ infection to levels similar to those observed in IL-15c-treated wt mice. Similarly, IL-15c treatment also significantly boosted RVinduced BAL (Figure 6c) and lung (Figure 6d)-activated $\mathrm{CD}^{+}$T-cell responses in wt mice. In IFNAR $1^{-/-}$mice, IL15c-stimulated $\mathrm{CD}^{+} \mathrm{T}$-cell responses were comparable to those observed in IL-15c-treated wt mice. CD4 ${ }^{+}$T-cell responses were also boosted with $\mathrm{IL}-15 \mathrm{c}$ treatment to similar levels in both wt and IFNAR1 ${ }^{-/-}$RV-infected mice compared with infection alone in the BAL (Figure 6e) and lung (Figure 6f). These results demonstrate that IL-15 can augment RV-induced lymphocyte responses independently of type I IFN signaling.

\section{IL-15c increased IL-15 and type I and type II IFN responses} To determine which IL-15-stimulated responses do not require type I IFN signaling during RV infection, we assessed expression of antiviral/Th1-associated molecules in wt and IFNAR1 ${ }^{-1-}$ mice following IL-15c treatment with RV infection. IL-15c enhanced both Il15 and Il15ro lung gene expression in wt and
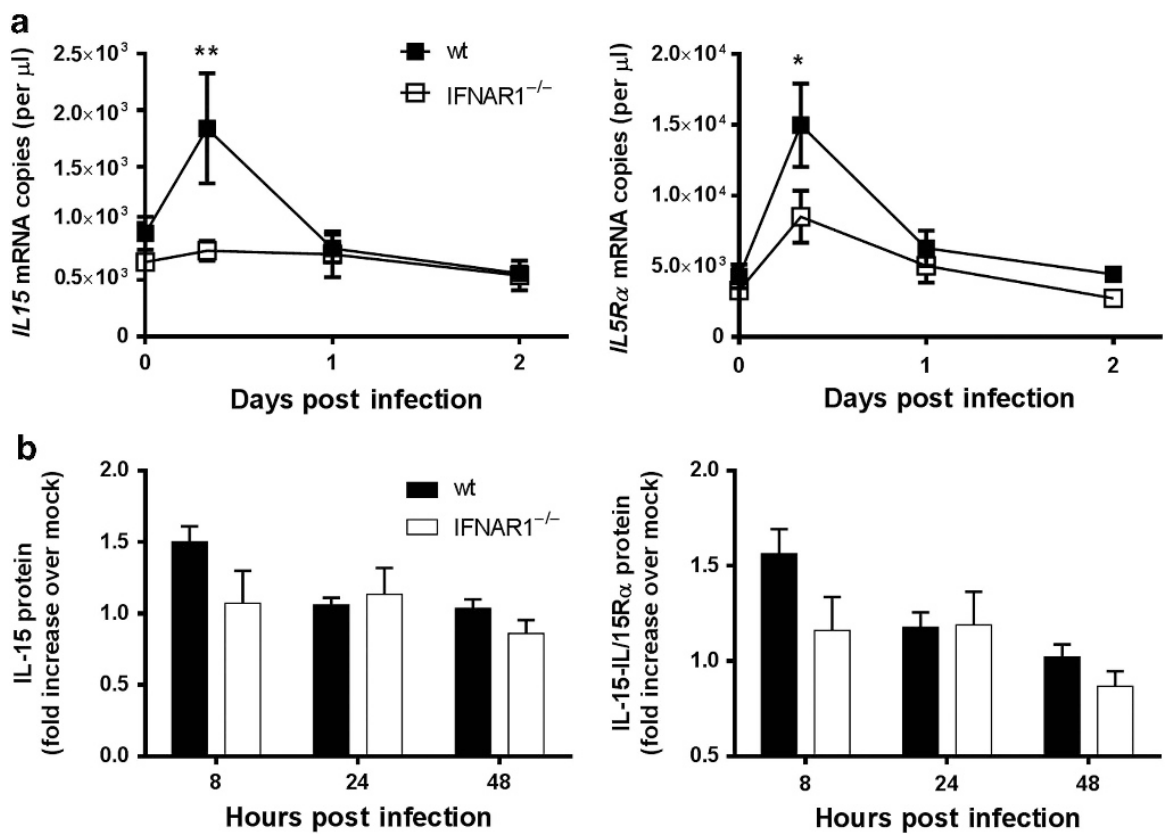

Figure 3 Type I IFN receptor is necessary for RV-induced IL-15 and IL-15R $\alpha$. IFNAR1 ${ }^{-1}$ - and wt strain-matched controls were either infected i.n. with $5 \times 10^{6} \mathrm{TCID}_{50}$ of RV-1B or dosed with PBS (mock/0 h post infection). (a) Levels of $/ / 15$ and $/ / 15 \mathrm{r} \alpha \mathrm{mRNA}$ were measured by qPCR in lung tissue. (b) IL-15 and soluble IL-15-IL-15R $\alpha$ complex (IL-15c) protein levels in lung homogenate expressed as fold increase over mock infected. All data are representative of three independent experiments, $n=4-6$ mice per group. Data were analyzed by two-way ANOVA, ${ }^{\star \star} P<0.01$ and ${ }^{\star} P<0.05$ as indicated, all data are expressed as mean \pm s.e.m. ANOVA, analysis of variance; IHC, immunohistochemistry; IL-15, interleukin-15; IFN, interferon; RV, rhinovirus.

Figure 2 Rhinovirus-induced IL-15 and IL-15R $\alpha$ gene and protein expression. BALB/c mice were either infected i.n. with $5 \times 10^{6} \mathrm{TCID}{ }_{50}$ of RV-1B or dosed with inactivated UV-RV-1B or PBS (mock infected/0 days post infection). (a, b) Levels of $/ / 15$ and $/ / 15 \mathrm{r} \alpha \mathrm{mRNA}$ were measured by qPCR in BAL cells (a) and lung tissue (b). (c) IL-15 and soluble IL-15-IL-15R $\alpha$ complex (IL-15c) protein levels in lung homogenate expressed as fold increase over mock infected. (d) Images of representative IHC staining for IL-15 protein in lung sections at $24 \mathrm{~h}$ and $48 \mathrm{~h}$ post infection (RV-1B) or treatment with UVinactivated virus (UV-RV-1B), mock infection (PBS) and normal goat serum staining control. Original magnification, $\times 400$. Bar $=50 \mu \mathrm{m}$. (e) Time course of IL-15 staining based on IHC score. (f) Time course of RV-1B viral load measured by qPCR in lung tissue. All data are representative of two to three independent experiments, $n=4-6$ mice per group. Data were analyzed by two-way ANOVA, ${ }^{* \star *} P<0.001,{ }^{* \star} P<0.01$ and ${ }^{\star} P<0.05$ as indicated, all data are expressed as mean \pm s.e.m. ANOVA, analysis of variance; IHC, immunohistochemistry; IL-15, interleukin-15; IFN, interferon; RV, rhinovirus. 
a

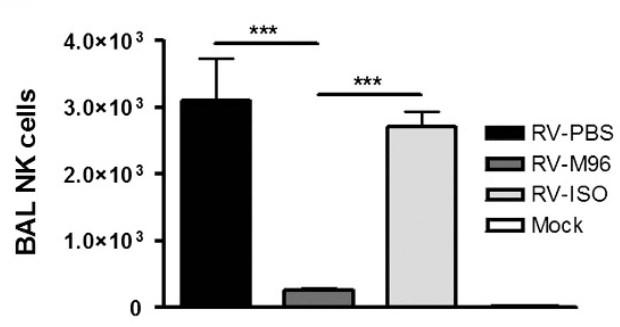

b

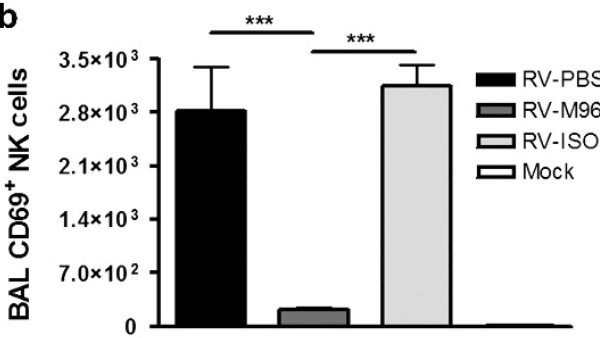

C

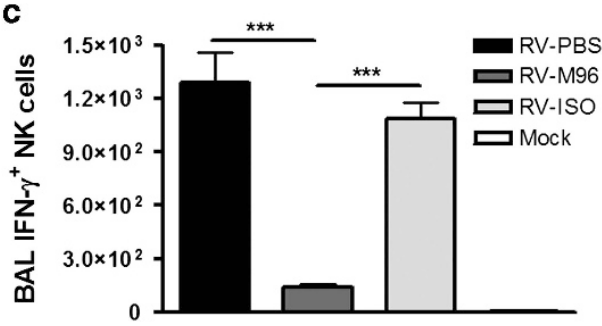

d

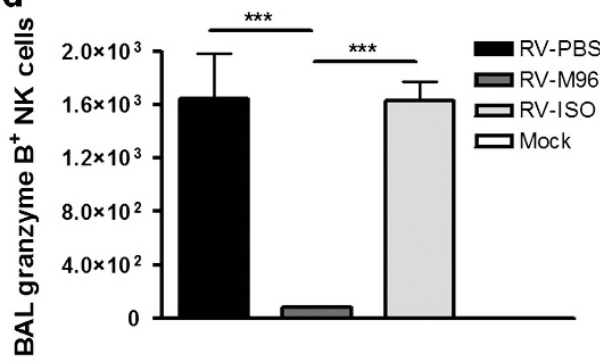

e

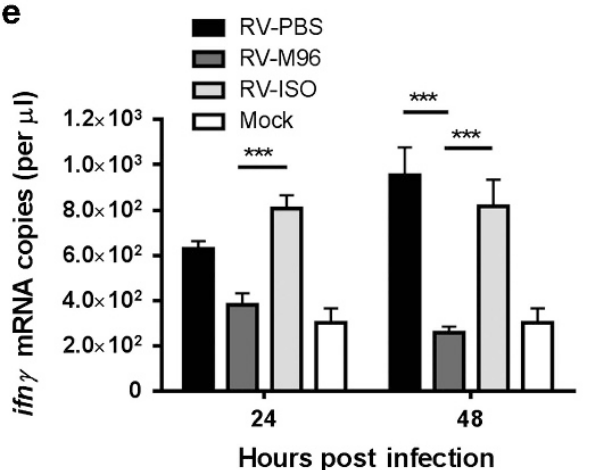

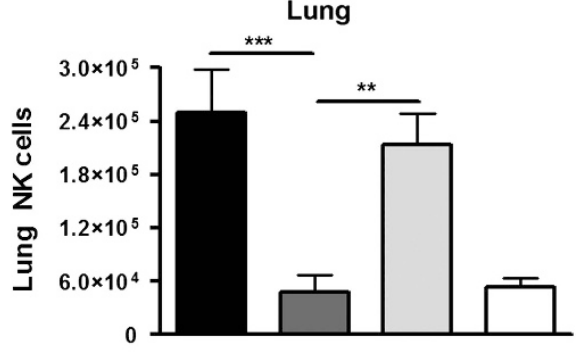
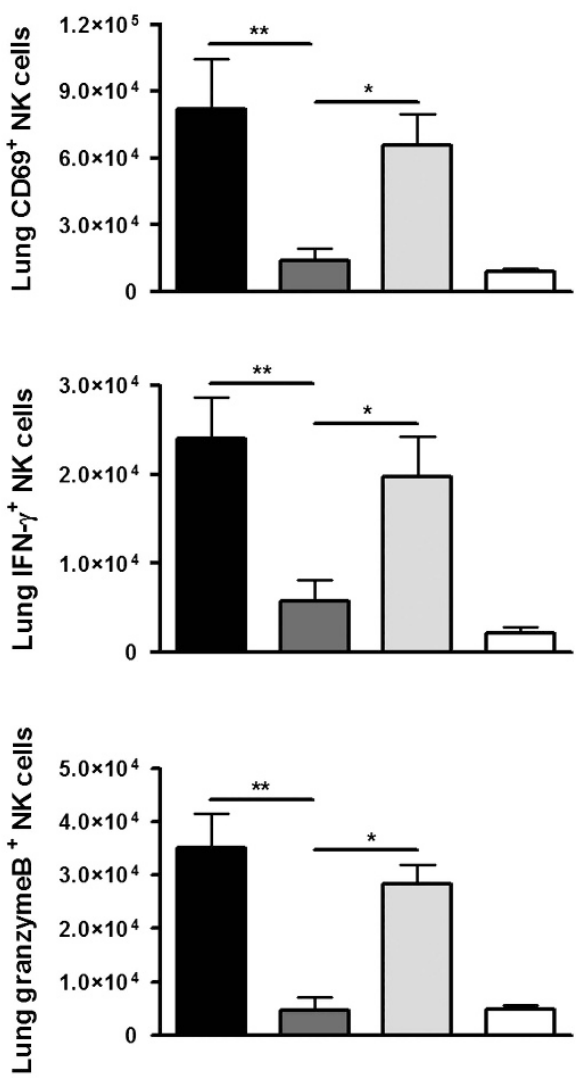

Figure 4 Rhinovirus-induced NK-cell responses were dependent on IL-15 signaling. BALB/C mice were either infected i.n. with $5 \times 10^{6} \mathrm{TCID}_{50}$ of RV-1B or dosed with PBS in addition to an IL-15-neutralizing antibody (M96), isotype control antibody, or PBS at the time of infection. (a-d) Flow cytometry was used to determine the total number of NK cells $\left(\mathrm{CD} 3^{-} \mathrm{NKp} 46^{+}\right)(\mathbf{a}), \mathrm{CD} 69^{+} \mathrm{NK}$ cells $(\mathbf{b}), \mathrm{IFN}-\gamma^{+} \mathrm{NK}$ cells $(\mathbf{c})$, and granzyme $\mathrm{B}^{+} \mathrm{NK}$ cells (d) in the BAL and lung tissue, at $48 \mathrm{~h}$ post infection. (e) Levels of Ifm $\gamma$ mRNA were measured by qPCR in lung tissue. All data are representative of two independent experiments, $n=4-7$ mice per group. Data were analyzed by two-way ANOVA, ${ }^{* \star *} P<0.001,{ }^{* \star} P<0.01$ and ${ }^{\star} P<0.05$ as indicated, all data are expressed as mean \pm s.e.m. ANOVA, analysis of variance; IHC, immunohistochemistry; IL-15, interleukin-15; IFN, interferon; NK, natural killer; RV, rhinovirus. 

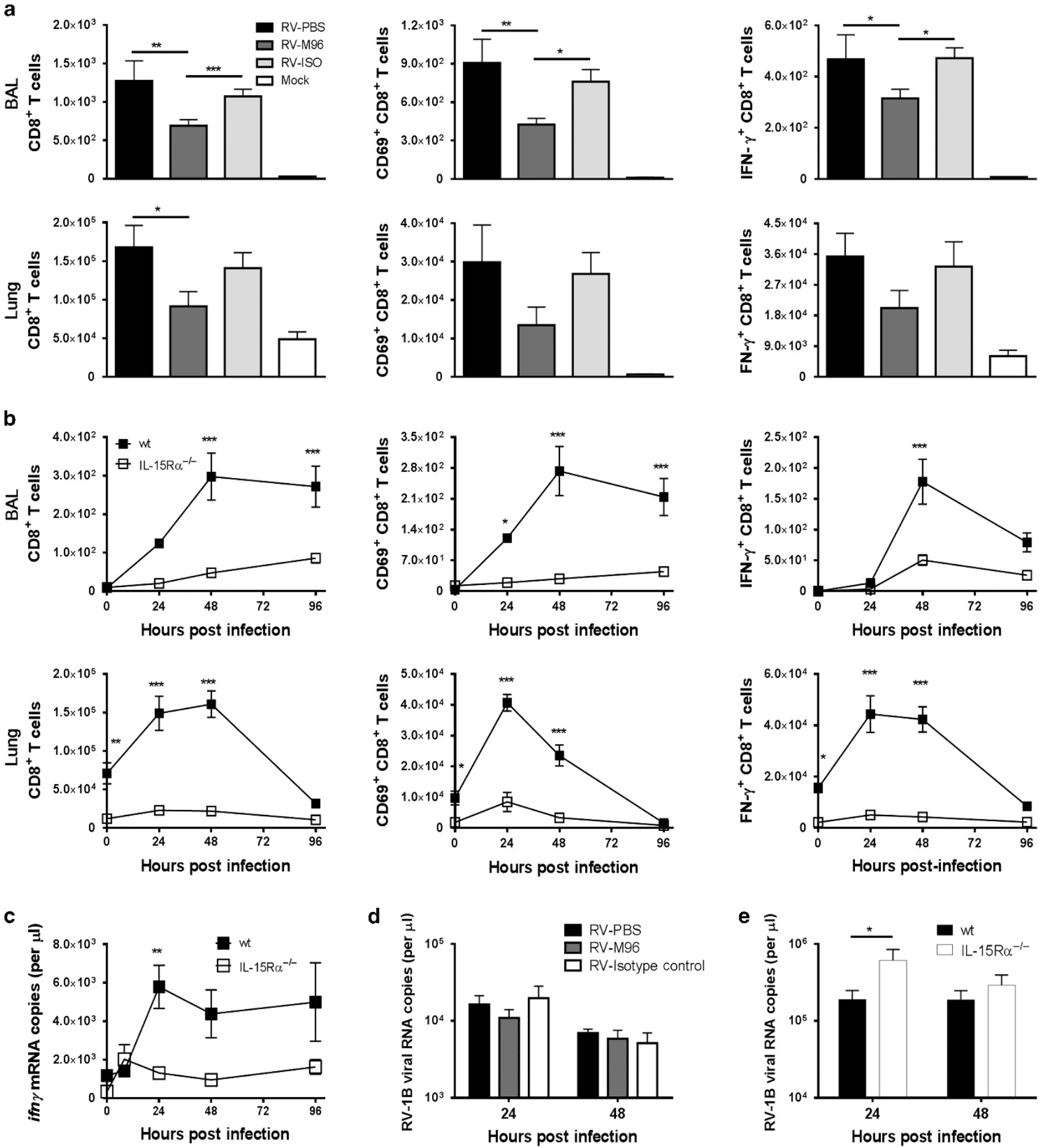

Figure 5 IL-15 signaling was important for $\mathrm{CD}^{+} \mathrm{T}$-cell responses during rhinovirus infection. BALB/c mice were either i.n. infected with $5 \times 10^{6} \mathrm{TCID}_{50}$ of RV-1B or dosed with PBS in addition to an IL-15-neutralizing antibody (M96), isotype control antibody or PBS at the time of infection. Alternatively, IL$15 \mathrm{R} \alpha^{-1-}$ and strain-matched control wt mice were either i.n. infected with $5 \times 10^{6} \mathrm{TCID}_{50}$ of RV-1B or dosed with PBS (mock/0 h post infection). Flow cytometry was used to determine the total number of $\mathrm{CD} 8^{+} \mathrm{T}$ cells $\left(\mathrm{CD} 3^{+} \mathrm{CD} 8^{+}\right), \mathrm{CD}_{6} 9^{+} \mathrm{CD}^{+} \mathrm{T}$ cells, and IFN- $\gamma^{+} \mathrm{CD} 8^{+} \mathrm{T}$ cells in the BAL and lung of (a) M96-treated BALB/c mice at $48 \mathrm{~h}$ post infection and (b) IL-15R $\alpha^{-1-}$ or wt mice at the indicated time points after treatment. (c) Levels of Ifm $\mathrm{mRNA}$ were measured by qPCR in lung tissue. Levels of RV-1B viral RNA in lung tissue were measured by qPCR to determine the viral load in (d). M96-treated $\mathrm{BALB} / \mathrm{c}$ mice and (e) IL-15R $\alpha^{-1-}$ and wt mice. All data are representative of two to three independent experiments, $n=4-7$ mice per group. Data were analyzed by two-way ANOVA, ${ }^{* \star \star} P<0.001,{ }^{\star \star} P<0.01$, and ${ }^{\star} P<0.05$ as indicated, all data are expressed as mean \pm s.e.m. ANOVA, analysis of variance; $\mathrm{IHC}$, immunohistochemistry; IL-15, interleukin-15; IFN, interferon; RV, rhinovirus.

IFNAR $1^{-/-}$mice (Figure 7a). There was a trend for increased If $n \beta$ gene expression in wt and IFNAR $1^{-1-}$ mice with IL-15c treatment (Figure $7 \mathbf{b}$ ), and this corresponded with significantly increased BAL IFN- $\beta$ protein levels in IFNAR $1^{-/-}$mice but no increase was detected in wt mice (Figure $7 \mathbf{b}$ ). IFN- $\alpha$ was poorly induced during $\mathrm{RV}$ infection in IFNAR $1^{-1-}$ mice in contrast to 

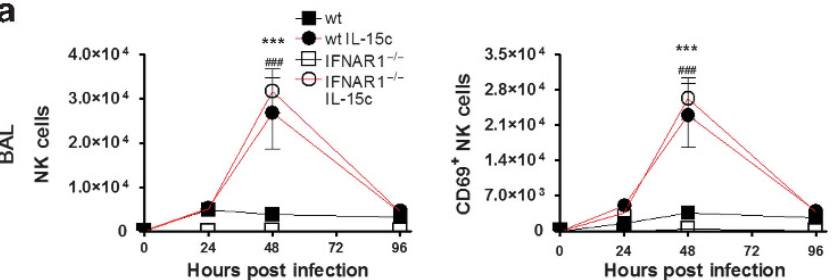

b
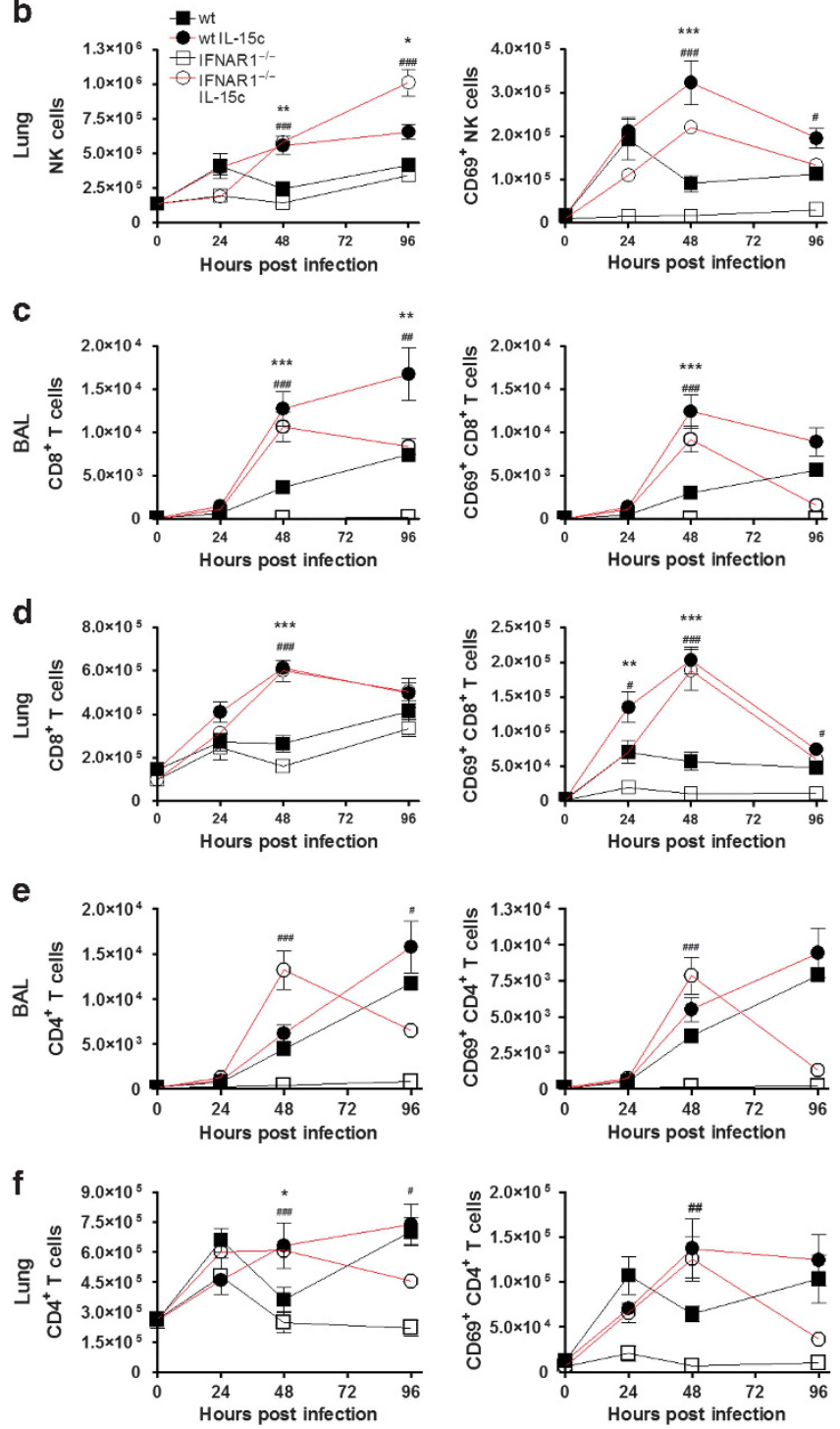
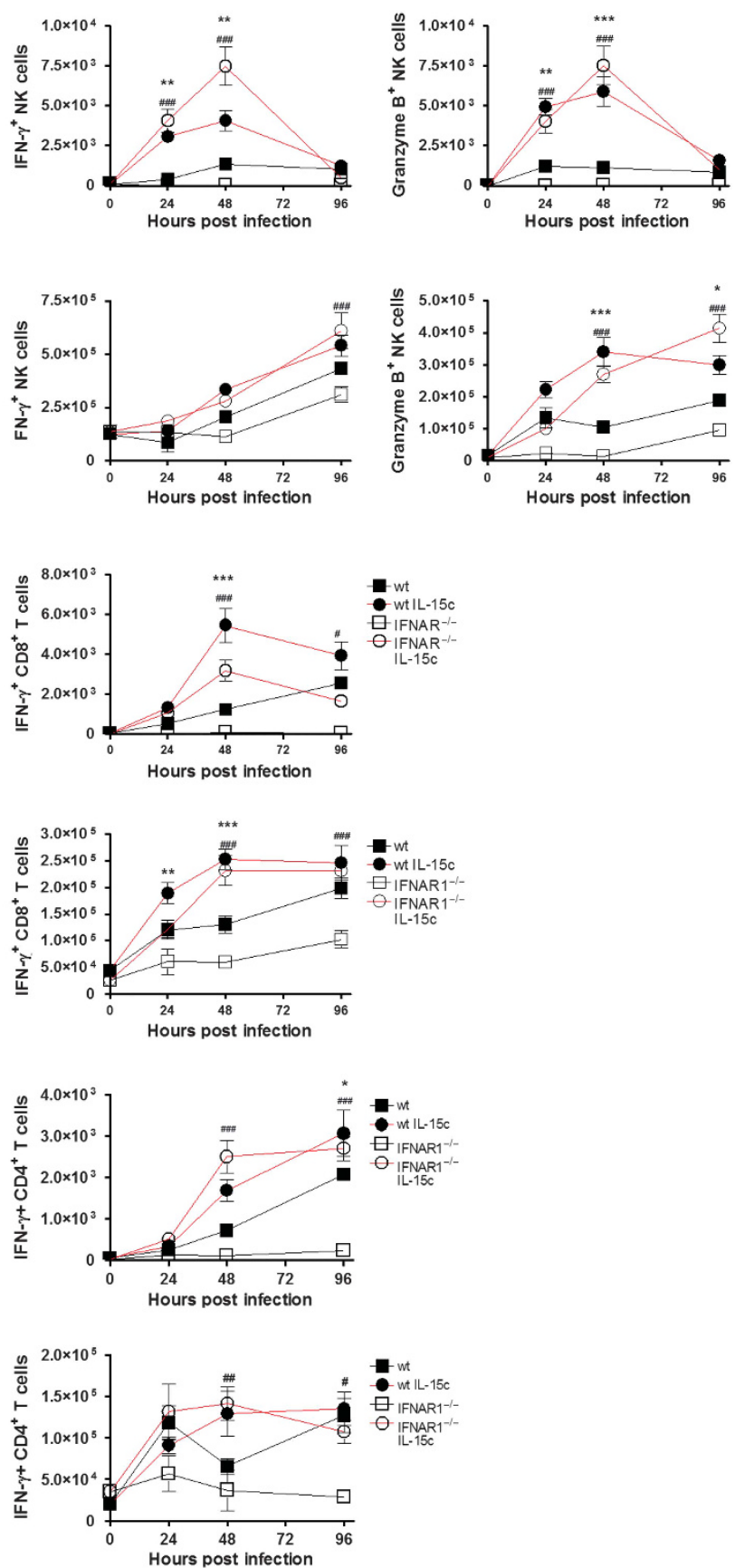

Figure $6 \mathrm{IL}-15$ complex restored NK-cell, $\mathrm{CD} 8^{+}$and $\mathrm{CD} 4^{+}$T-cell responses in the absence of type I IFN receptor signaling. IFNAR1 ${ }^{-/-}$and strainmatched wt control mice were either infected with $5 \times 10^{6} \mathrm{TCID}_{50}$ of RV-1B i.n. or dosed with PBS (mock/0 h post infection) in the absence or presence of IL-15-IL-15R $\alpha$ complex (IL-15c). (a-f) Flow cytometry was used to determine the time course of total numbers of NK cells $\left(\mathrm{CD}^{-} \mathrm{NKp}^{-} 6^{+}\right), \mathrm{CD}^{-} 9^{+} \mathrm{NK}^{-}$ cells, IFN- $\gamma^{+} \mathrm{NK}$ cells, and Granzyme B ${ }^{+} \mathrm{NK}$ cells in the BAL (a) and lung (b); $\mathrm{CD} 8^{+} \mathrm{T}_{\text {cells }}\left(\mathrm{CD} 3^{+} \mathrm{CD}^{+}{ }^{+}\right), \mathrm{CD} 69^{+} \mathrm{CD}^{+} \mathrm{T}^{+}$cells and, IFN- $\gamma^{+} \mathrm{CD} 8{ }^{+} \mathrm{T}$ cells in the BAL (c) and lung (d); and $\mathrm{CD} 4^{+} \mathrm{T}$ cells $\left(\mathrm{CD} 3^{+} \mathrm{CD} 4^{+}\right), \mathrm{CD} 69^{+} \mathrm{CD} 4^{+} \mathrm{T}$ cells and IFN- $\gamma^{+} \mathrm{CD} 4^{+} \mathrm{T}$ cells in the BAL (e) and lung (f) at the indicated time points post infection. All data are representative of three independent experiments, $n=4-6$ mice per group. Data were analyzed by twoway ANOVA, ${ }^{\# \# \# / * \star \star} P<0.001,{ }^{\# \# / * \star} P<0.01$ and ${ }^{\# / *} P<0.05$ as indicated, all data are expressed as mean \pm s.e.m. ${ }^{*}$ refers to wt vs. wt IL-15c groups and ${ }^{\#}$ refers to IFNAR $1^{-1-}$ vs. IFNAR1 ${ }^{-1-}$ IL-15c groups. ANOVA, analysis of variance; IHC, immunohistochemistry; IL-15, interleukin-15; IFN, interferon; $\mathrm{RV}$, rhinovirus.

wt mice. Even so, IL-15c treatment was able to significantly increase the detectable level of BAL IFN- $\alpha$ protein in IFNAR $1^{-/-}$mice. For wt, mice despite robust induction, IL-15c actually reduced the level of IFN- $\alpha$. IL-15c treatment significantly increased IFN- $\lambda$ mRNA expression in both RVinfected wt and IFNAR $1^{-/-}$mice; however, corresponding increases in BAL IFN- $\lambda$ protein were only significant in IFNAR $1^{-1-}$ mice (Figure $7 \mathbf{b}$ ). Furthermore, despite similar 


\section{a}

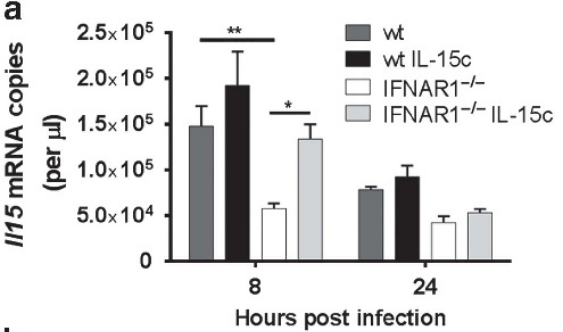

b
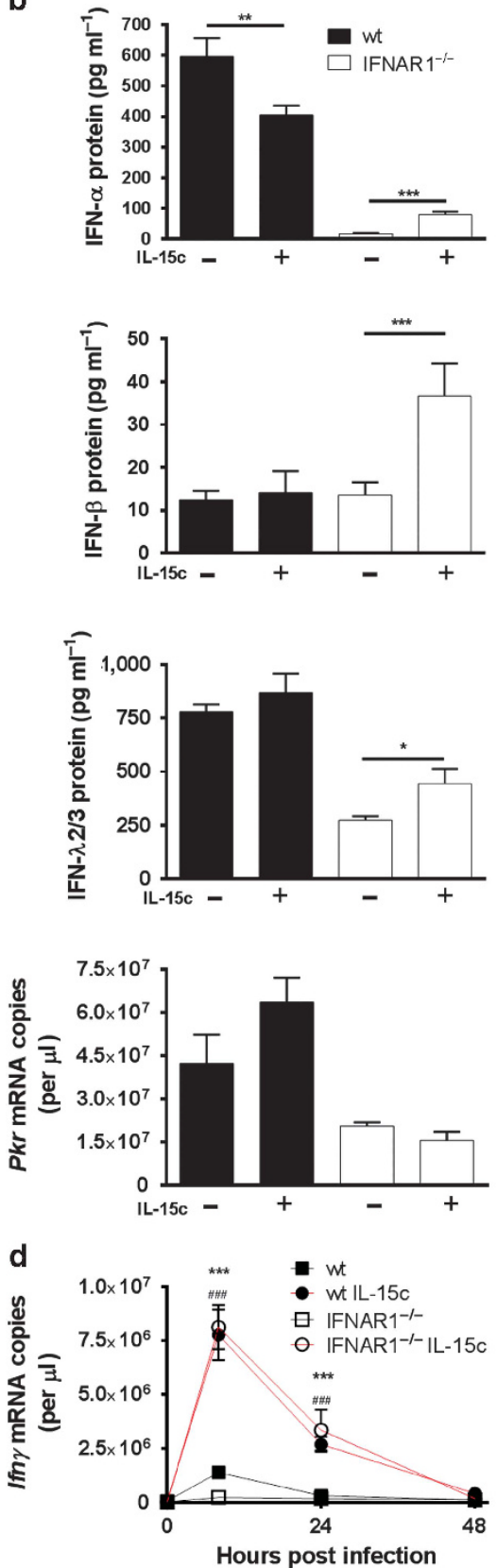
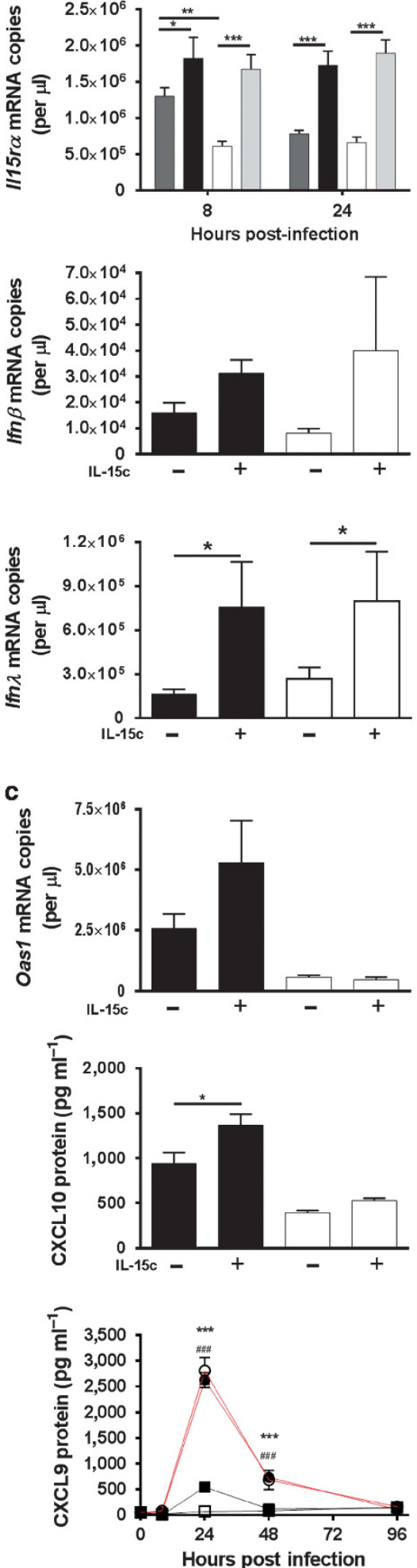

Figure 7 IL-15c administration during rhinovirus infection boosts expression of IL-15, IL-15R $\alpha$, type I, II, and III IFNs, and ISGs. IFNAR1 ${ }^{-/-}$and strainmatched control wt mice were either infected i.n. with $5 \times 10^{6} \mathrm{TCID}_{50}$ of RV-1B or dosed with PBS (mock/0 h post infection) in the presence or absence of IL-15c. (a) Levels of I/15 and I/15r $\alpha$ mRNA were measured by qPCR in lung tissue at 24 and $48 \mathrm{~h}$ post infection. (b) Levels of IFN- $\alpha$, IFN- $\beta$, and IFN- $\lambda 2 / 3$ protein in BAL fluid were measured by ELISA and Ifn $\beta$ and Ifn $\lambda$ mRNA in lung tissue by qPCR at $24 \mathrm{~h}$ post infection. (c) Expression of ISGs Pkrand Oas 1 mRNA in lung tissue and CXCL10 protein in BAL $24 \mathrm{~h}$ post infection. (d) Lung Ifm mRNA and CXCL9 protein in BAL fluid $24 \mathrm{~h}$ post infection; ${ }^{*}$ refers to wt vs. wt IL-15c groups and " refers to IFNAR1 ${ }^{-1-}$ vs. IFNAR1 ${ }^{-1-} \mathrm{IL}-15 \mathrm{c}$ groups. All data are representative of two to three independent experiments, $n=4-6$ mice per group. Data were analyzed by two-way ANOVA, ${ }^{\# \# \# / * \star *} P<0.001,{ }^{* \star} P<0.01$ and ${ }^{*} P<0.05$ as indicated, all data are expressed as mean \pm s.e.m. ANOVA, analysis of variance; IHC, immunohistochemistry; IL-15, interleukin-15; IFN, interferon; RV, rhinovirus. 

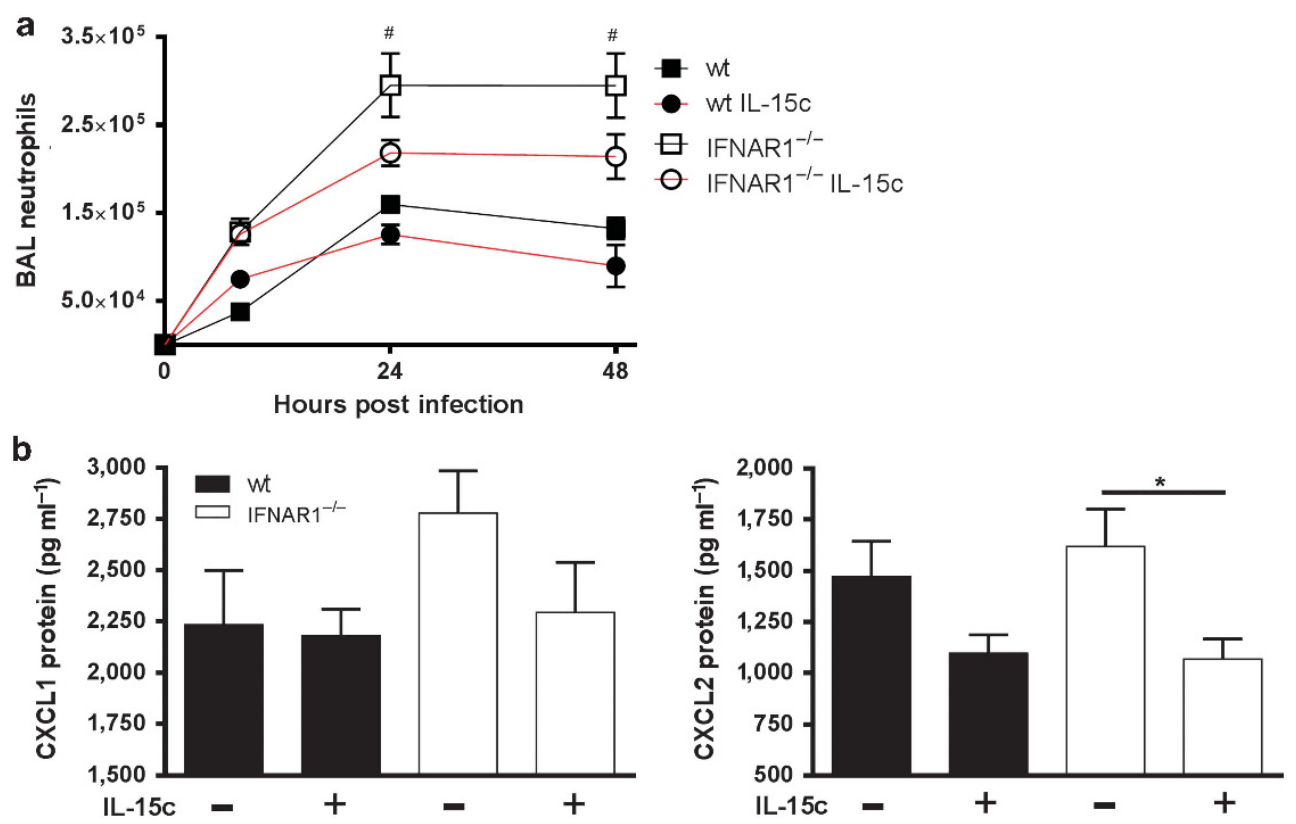

Figure 8 IL-15c suppressed exacerbated neutrophilic inflammation and associated chemokine expression in RV-infected type I IFN receptor-deficient mice. IFNAR1 ${ }^{-1-}$ and wt mice were either infected i.n. with $5 \times 10^{6} \mathrm{TCID}_{50}$ of RV-1B or dosed with PBS (mock/0 h post infection) in the absence or presence of IL-15c. (a) Timecourse of neutrophils in the BAL was assessed by differential cell counts, at the indicated time points after treatment; ${ }^{\#}$ refers to IFNAR1 ${ }^{-1-}$ vs. IFNAR1 ${ }^{-1-}$ IL-15c groups. (b) Neutrophil chemokines CXCL1 and CXCL2 were analyzed in BAL fluid $8 \mathrm{~h}$ post infection by ELISA. All data are representative of two to three independent experiments, $n=4-6$ mice per group. Data were analyzed by two-way ANOVA, ${ }^{\# / *} P<0.05$ as indicated, all data are expressed as mean \pm s.e.m. ANOVA, analysis of variance; IHC, immunohistochemistry; IL-15, interleukin-15; IFN, interferon; RV, rhinovirus.

levels of IFN- $\lambda$ mRNA detected in corresponding treatment groups of wt and IFNAR1 ${ }^{-1-}$ mice, greater levels of protein was observed in wt mice.

We have previously shown full induction of the ISGs $2^{\prime}-5^{\prime}$ oligoadenylate synthetase 1 (Oas1), protein kinase $\mathrm{R}(P k r)$, and CXCL10 during RV infection required expression of type I IFN receptor. ${ }^{10} \mathrm{IL}-15 \mathrm{c}$ treatment augmented RV-induced expression of (Oas1) mRNA, (Pkr) mRNA, and CXCL10 protein in wt mice; however, statistical significance was only reached for increased CXCL10 expression (Figure 7c). IL-15c treatment also significantly increased lung Ifn $\gamma$ gene expression at $8 \mathrm{~h}$ p.i., which was followed by significantly increased production of CXCL9 at $24 \mathrm{~h}$ p.i. in wt and IFNAR1 ${ }^{-1-}$ mice to equal levels (Figure 7d). These data show that IL-15c treatment greatly boosted expression of IFN- $\gamma$ and IFN- $\gamma$ stimulated chemokines during RV infection via a type I IFNindependent mechanism.

\section{IL-15c treatment reduced airway neutrophilic inflammation}

A feature of the response to RV infection in human and mouse models is neutrophilic inflammation and this is exacerbated by IFN deficiency. ${ }^{10}$ We compared airway neutrophilia following $\mathrm{RV}$ infection observing a significant increase in IFNAR1 ${ }^{-1-}$ mice compared with wt as previously reported. IL-15c treatment reduced the numbers of neutrophils in the airways of IFNAR $1^{-1-}$ mice (Figure 8a). This was associated with reduced expression of the neutrophil-recruiting chemokines CXCL1 and CXCL2 at $8 \mathrm{~h}$ p.i. (Figure 8 b), and by $24 \mathrm{~h}$ p.i. levels had declined to baseline in all groups (data not shown).

\section{DISCUSSION}

Despite their dominant role in respiratory diseases globally, much is still unknown about the immunopathogenesis of RV infections. In this study, we first used a human experimental RV infection model observing increased IL-15 protein expression in the upper and lower respiratory tract. The nasosorption method of repeated sampling of the upper respiratory tract provided undiluted samples of nasal mucosal lining fluid that allowed detection of numerous immune mediators. This enabled us to detect IL-15 protein (as well as many other immune mediators) directly in the mucosa of both the upper and lower airways during RV infection, a first for RV and indeed for any respiratory virus.

RVs primarily replicate in nasal epithelial cells of the upper respiratory tract and cause the common cold. RVs can also infect the lungs but usually only cause disease when infection exacerbates a pre-existing respiratory condition such as asthma ${ }^{30}$ or COPD. ${ }^{28}$ To study 'normal' host immunity to $\mathrm{RV}$ infection in the absence of pre-existing respiratory disease, we employed a mouse RV infection model. This involved delivery of a high dose of RV-1B that, while not designed to model human disease per se, is widely used to study immunity to $\mathrm{RV}$ as it generates robust and reproducible inflammatory and antiviral immune responses in commonly used mouse strains including Balb/c, ${ }^{9} \mathrm{C} 57 \mathrm{BL} / 6,{ }^{31}$ and B6.129, ${ }^{10}$ which were the strains used in this study. For all of these mouse strains, it was reported that RV infection induced an acute neutrophilic response accompanied by expression of neutrophil-recruiting chemokines, proinflammatory cytokines, and interferons. This 
was followed by expression of lymphocyte-recruiting chemokines, resolution of neutrophilic inflammation, and recruitment of lymphocytes to the lungs.

Investigation of the role of IL-15 is complicated by constitutive expression and requirement for NK-cell homeostasis. This potentially contributed to the modest induction levels of IL-15 protein expression observed during RV infection in human and mouse models. We employed two strategies to block IL-15 activity during RV infection. The first involved lung delivery of an IL-15-neutralizing antibody to transiently block IL-15 during infection. In uninfected mice, this eventually caused a 50\% reduction in lung NK cells after 2 days. During infection, IL-15 neutralisation (at the time of infection so NKcell numbers intact) almost completely ablated lung tissue and airway NK-cell responses providing direct evidence that IL-15 is required for acute $\mathrm{NK}$-cell responses during $\mathrm{RV}$ infection. We also studied IL-15R $\alpha^{-1-}$ mice that have a constitutive severe deficiency of NK cells and lower numbers of $\mathrm{CD} 8^{+} \mathrm{T}$ cells in the lungs at baseline. IL-15R $\alpha^{-1-}$ mice had severely deficient $\mathrm{CD}^{+}{ }^{+} \mathrm{T}$-cell responses, demonstrating that IL- 15 is necessary for recruitment of activated IFN- $\gamma$-expressing $\mathrm{CD} 8^{+} \mathrm{T}$ cells. Reduced CD8 ${ }^{+} \mathrm{T}$-cell responses were also observed with IL-15 neutralisation by an antibody during infection; however, the reduction was modest.

Despite having profound effects on host immune responses, IL-15 activity only modestly influenced viral replication. IL$15 \mathrm{R} \alpha^{-1-}$ mice had a transient increase in viral load. Anti-IL-15 antibody treatment had no effect on levels of lung viral RNA. This difference is associated with the different degrees of $\mathrm{CD}^{+}$ T-cell deficiency discussed above. Little is known about the kinetics of RV replication in the human lung, as it is technically difficult to repeatedly sample individual subjects during infection. ${ }^{32}$ In the absence of this information, it is difficult to interpret lung replication data in the mouse. Also the dose of virus required to induce robust pulmonary immune responses in mice is high and did not reflect a natural infection in humans, which usually does not induce substantial lower respiratory tract inflammation. Thus, RV replication data in the mouse should be interpreted with caution particularly in the absence of good human in vivo lung infection data to support such analyses.

This is the first in vivo demonstration of type I IFNdependant IL-15 and IL-15R $\alpha$ upregulation in response to RV infection. IHC staining indicated that IL- 15 was predominantly expressed on the apical surface of epithelial cells lining the airway as well as infiltrating leukocytes in the subepithelium. The location and morphology of these cells was consistent with them being activated DCs that are part of the complex network that lie directly beneath the airway epithelial layer. ${ }^{33}$ McGill et al. ${ }^{17}$ demonstrated higher levels of surface IL-15 on pulmonary plasmacytoid (pDCs) and CD $8 \alpha^{+}$DCs compared with alveolar macrophages after influenza infection, and IL-15 trans-presentation by these $\mathrm{DC}$ subsets promoted CD $8{ }^{+} \mathrm{T}$-cell survival and accumulation in the lungs.

We demonstrate that, even in the absence of type I IFN signaling, previously reported to be critical for activation of antiviral NK cell and CD8 ${ }^{+}$T-cell responses, IL-15c was able to rescue these responses and even boost them above levels observed in wt mice. Thus, we have identified IL-15 (and IL$15 R \alpha)$ as the only ISGs necessary for these key antiviral lymphocyte responses. One other study has demonstrated the ability of exogenous IL-15 to mediate the accumulation of proliferating NK cells independently of type I IFNs; ${ }^{22}$ however, the effect on activation of antiviral lymphocyte subsets and IFN- $\gamma$ expression during virus infection was not investigated. We observed rapid and enhanced induction of lung If $n \gamma$ mRNA followed by CXCL9 protein expression, which preceded the increased recruitment of IFN- $\gamma$-expressing NK and T cells with IL-15c treatment. These data identify the capacity of IL-15 to mediate Ifn $\gamma$ expression and lymphocyte responses independently of type I IFN signaling in vivo.

A key question is how does IL-15c restore NK- and Th1-cell responses during RV infection in the absence of ISG expression? Especially since many lymphocyte-recruiting chemokines such as CXCL10 are induced by type I IFN signaling, which are deficient in RV-infected IFNAR1 ${ }^{-1-}$ mice. ${ }^{10}$ This raises the possibility that the IL-15c-augmented early IFN- $\gamma$ expression induced production of nontype I IFN-dependant chemokines, which could recruit NK and T cells to the lung. CXCL9, CXCL10, and CXCL11 all bind CXCR3 on NK cells and CD4 ${ }^{+}$ and $\mathrm{CD}^{+} \mathrm{T}$ cells to mediate chemotaxis to sites of inflammation. Although originally described as interferon gamma-inducible protein 10 (IP-10), IL-15c treatment failed to induce CXCL10 production in IFNAR1 ${ }^{-/-}$mice (despite robust Ifn $\gamma$ expression), whereas RV-induced expression was further boosted in wt mice, suggesting that CXCL10 is dependent on type I rather than type II IFNs. In contrast, we observed robust expression of CXCL9 (originally identified as monokine induced by gamma interferon) in both wt and IFNAR $1^{-1-}$ mice peaking at $24 \mathrm{~h}$. The requirement of IFN- $\gamma$ for CXCL9 expression has been observed during Klebsiella infection using IFN- $\gamma$ knockout mice. ${ }^{34}$ Pertaining to lung responses, treatment of cultured human bronchial epithelial cells with IFN- $\gamma$ induced CXCL9 expression. ${ }^{35}$ We suggest that the early induction of Ifny gene expression in the lung, potentially stimulated by the combination of RV infection/ TLR activation signals in conjunction with enhanced IL-15c stimulation of resident DCs and macrophages, was critical to recruitment of IFN- $\gamma$-expressing NK cells and T cells via enhanced expression of CXCL9. We have previously demonstrated that human macrophages infected with $\mathrm{RV}$ in vitro produce IFN- $\gamma .^{30}$ This is the first report to our knowledge demonstrating RV infection in vivo induces expression of CXCL9 in the airways, which is potentially the critical CXCR3binding chemokine necessary for recruitment of NK cells and $\mathrm{CD}^{+}{ }^{+} \mathrm{T}$ cells to lungs/airway. IL-15 is also reported to have direct chemotactic effects on NK cells and $\mathrm{CD} 8{ }^{+} \mathrm{T}$ cells as demonstrated by migration through transwell systems to IL-15 supplemented media. ${ }^{36,37}$ The increased numbers of NK cells observed following exogenously administered IL-15 may have also been a result of proliferation within the lung as IL-15 has been reported to stimulate NK-cell proliferation during cytomegalovirus and influenza infection..$^{22,37}$ 
IL-15c augmented expression of ISGs (OAS1, PKR, and CXCL10) in wt mice during RV infection, which we suspect was through increased signaling from the type I IFN receptor. However, while Ifn $\beta$ mRNA was increased, BAL IFN- $\beta$ protein levels were not, and BAL IFN- $\alpha$ protein was actually lower in the IL-15c-treated group. This was potentially due to increased type I IFN receptor expression with IL-15c treatment, resulting in increased ligand binding and less free detectable IFN in the BAL. This hypothesis is supported by the increased BAL type I IFN proteins observed in IL-15c/RV-treated IFNAR1 ${ }^{-/-}$ mice. One study has reported the capacity of IL-15 to induce IFN- $\beta$ expression in macrophages in vitro, ${ }^{38}$ whereas another report described IL-15-induced type I IFN by cultured human DCs. ${ }^{39}$ IL-15c treatment also augmented type III IFN production independently of type I IFN signaling. This study is the first to demonstrate that IL-15 treatment can augment IFN and ISG expression during a viral infection in vivo. Although IL-15c treatment could boost ISG expression through increased type I IFN signaling, the increased endogenous Il15 and IL15r $\alpha$ expression detected also occurred in the absence of type I IFN signaling, suggesting that IL-15 was capable of increasing its own expression and signaling independently of type I IFN. Boosted expression of IL-15 and its receptor, in conjunction with endosomal recycling of membrane-bound IL15-IL-15R $\alpha$ complexes, which allows longer and persistent IL15 signalling, ${ }^{40,41}$ could contribute to the enhanced lymphocyte responses and cytokine and chemokine expression detected in IL-15c-treated mice.

Our data provide novel insight into the immune response to $\mathrm{RV}$ infection providing first in vivo evidence of the importance of IL-15 for NK-cell, CD8 ${ }^{+}$T-cell, and CD4 + T-cell responses to $\mathrm{RV}$ infection. In addition, we have identified a novel function for IL-15 in augmenting antiviral IFN- $\gamma$ expression and lymphocyte responses independently of type I IFNs. Our data suggest that boosting NK and CD8 + T-cell responses during RV infection in healthy subjects is unlikely to provide substantial benefit, as the virus is efficiently cleared without causing disease. In the case of asthma exacerbations, RV infection can augment lung inflammation driven by type- 2 immunity. In this case, we would predict that increasing IFN- $\gamma$ production by recruitment of IL-15-activated NK and CD $8+\mathrm{T}$ cells may inhibit production of type- 2 cytokines and associated immunopathological responses such as airway hyper-reactivity and mucus secretion. Asthmatic bronchial epithelial cells also exhibit deficient antiviral responses and are more permissive for viral replication. ${ }^{27}$ Boosting antiviral cellular responses may also compensate for this asthma-associated immune defect. Our data support the view that therapeutic administration of IL-15c during asthma exacerbations would be the most beneficial approach with the important caveat that therapeutic administration of IL-15c has the potential to induce exaggerated type-1 immune responses with excessive IFN- $\gamma$ production and associated airways inflammation. ${ }^{42}$ Thus, IL-15c must be developed and used with caution. This could be achieved by detailed titration studies to identify a dose range that stimulates type-1 immunity that is sufficient for better control of viral infections and suppression of type-2-driven inflammation and results in a net reduction in airways inflammation and disease.

\section{METHODS}

Human experimental rhinovirus infection and measurement of nasal cytokines. Two cohorts of 11 healthy, nonsmoking volunteers with no history of asthma or respiratory disease, negative skin prick tests, no evidence of bronchial hyper-reactivity $\left(\mathrm{PC}_{20}>8 \mathrm{mg} \mathrm{ml}^{-1}\right)$ and no cold in the last 6 weeks were entered in this study. Infection was induced with rhinovirus serotype 16 via nasal spray into both nostrils. ${ }^{30}$ For one cohort, nasal responses were measured. Before RV infection (baseline) and at days 2, 3, 4, 5, 7, and 10 post inoculation, the Nasosorption technique ${ }^{43-45}$ was used to sample soluble mediators in the nasal mucosa. IL-15 was measured using the Meso-Scale Discovery (MSD) platform (sensitivity of $<0.6 \mathrm{pg} \mathrm{ml}^{-1}$ ). The second cohort has been described previously. ${ }^{30}$ Bronchial biopsies were obtained at baseline ( 2 weeks before infection) and at day 4 after infection.

Mouse rhinovirus infection. IL-15R $\alpha^{-/-}$mice on a B6.129 background, B6.129 control mice (both purchased from the Jackson Laboratory, Bar Harbor, ME), and IFNAR $1^{-1-}$ mice on a C57BL/6 background were bred in house under specific pathogen-free conditions. Balb/c and C57BL/6 control mice were purchased from Harlan (Harlan-Sprague-Dawley, Shardlow, UK). Rhinovirus sertotype 1B (RV-1B) obtained from the American Type Culture Collection (Salisbury, UK) was grown in HeLa cells (European Collection of Cell Cultures) and purified for in vivo use as previously described. ${ }^{9}$ The virus was inactivated by exposure to UV light at $1,200 \mathrm{~mJ} \mathrm{~cm}^{-2}$ for $30 \mathrm{~min}$. Mice were lightly anesthetized with isofluorane and infected intra-nasally (i.n.) with $50 \mu \mathrm{l}$ of RV-1B $\left(5 \times 10^{6} \mathrm{TCID}_{50}\right)$ or PBS (mock-infected represented as $0 \mathrm{~h}$ in time course studies). All mouse experiments were performed using 6- to 8-week-old mice, and only female mice were used in studies involving wt Balb/c, wt B6.129, and IL- $15 \mathrm{R} \alpha^{-1-}$ mice, and males and females were used in studies involving wt $\mathrm{C} 57 \mathrm{BL} / 6$ and IFNAR $1^{-/-}$mice.

Anti-IL-15 antibody and IL-15 complex treatment. Balb/c mice were treated i.n. with $20 \mu \mathrm{g}$ of an IL-15-neutralizing antibody (M96, Amgen, Thousand Oaks, CA) or mouse IgG2a isotype control (R\&D Systems, Abingdon, UK) at the time of infection $(0 \mathrm{~h})$ and $24 \mathrm{~h}$ after infection. In other studies, IFNAR $1^{-1-}$ and C56BL/ 6 control mice were treated i.n. with $1.5 \mu \mathrm{g}$ IL-15 complexed to IL-15R $\alpha$ (IL-15c) (eBiosciences, Hatfield, UK) at the time of infection.

Cytokine ELISA. For BAL fluid, ELISAs for mouse IFN- $\alpha$, IFN- $\beta$, IFN$\lambda 2 / 3$ (IL-28A/B), CXCL9, and CXCL10 (R\&D Systems) were used. The right azygous, cardiac and diaphramic lung lobes were excised post BAL and homogenized in PBS with EDTA-free protease cocktail inhibitor (Roche, Indianapolis, IN); the clarified supernatant after centrifugation was used for IL-15 (R\&D Systems) and IL-15c (eBiosciences) ELISAs according to the manufacturer's recommended protocol.

TaqMan quantitative real-time PCR. The mouse apical lung lobe was excised and stored in RNA later (Qiagen, Manchester, UK) before total RNA extraction (RNeasy miniprep kit, Qiagen), and $5 \mu \mathrm{g}$ of RNA was reverse-transcribed for cDNA synthesis using random hexamers as primers (Omniscript RT kit, Qiagen). RNA from BAL cells was also extracted and converted to CDNA by the same process. Quantitative PCR was conducted using primers and probes specific to each gene analyzed, using an ABI 7500 TaqMan (ABI Foster City, CA). Each gene was normalized to $18 \mathrm{~s}$ rRNA and expressed as mRNA copies per microliter of cDNA reaction, quantified by a standard curve from amplified plasmid DNA standards.

Immunohistochemistry. Human bronchial biopsies were embedded in Tissue Tek II OCT, frozen within $15 \mathrm{~min}$ in isopentane pre-cooled in 
liquid nitrogen, and stored at $-80{ }^{\circ} \mathrm{C}$. The best frozen sample was then oriented and $6 \mu \mathrm{m}$ thick cryostat sections were cut for immunohistochemical light microscopy analysis. After blocking nonspecific binding, $1.3 \mu \mathrm{g} \mathrm{ml}^{-1}$ mouse anti-human IL-15 (Santa Cruz Biotechnology sc-73311, Dallas, TX) were applied for $1 \mathrm{~h}$ at room temperature in a humidified chamber. As positive control, we have used human nasal polyps and these were used for negative control slides, which were treated with normal mouse nonspecific immunoglobulins (Santa Cruz Biotechnology). After repeated washing steps with TBS, the sections were subsequently incubated with a horse antimouse biotinylated antibody (Vectastain Elite ABC Kit, Vector Laboratories, Peterborough, UK) for $30 \mathrm{~min}$ at room temperature. After further washing, the sections were subsequently incubated with $A B C$ reagent (Vectastain Elite $A B C$ Kit, Vector Laboratories) for $30 \mathrm{~min}$ at room temperature. Slides were then incubated with chromogen-fast diaminobenzidine (DAB) as a chromogenic substance, after which they were counterstained in haematoxylin and mounted on aqueous mounting medium.

Single IHC staining of mouse lung sections from formalin-fixed paraffin-embedded mouse lungs was performed as previously described. ${ }^{10}$ After blocking slides (5\% rabbit serum), goat anti mouse IL-15 (RnD Systems AF447) was applied at $4 \mu \mathrm{g} \mathrm{ml}^{-1}$. For the negative control slides, normal goat nonspecific immunoglobulins (Santa Cruz Biotechnology) were used. The intensity and distribution of positive staining in human biopsies and mouse lung sections was evaluated using a standard four point scale, with sections being scored as $0,1,2$, or 3 according to a validated method. ${ }^{46}$

Flow cytometry. The left lung lobe was excised post BAL, crudely dissociated using the GentleMACS tissue dissociator (Miltenyi Biotech, Surrey, UK) and digested upon incubation at $37^{\circ} \mathrm{C}$ in buffer containing $1 \mathrm{mg} \mathrm{ml}^{-1}$ collagenase Type XI and 80 units $\mathrm{ml}^{-1}$ Bovine Pancreatic DNase Type IV (both Sigma-Aldrich, Dorset, UK). For intracellular cytokine staining (ICS), cells were stimulated with PMA $\left(50 \mathrm{ng} \mathrm{ml}^{-1}\right)$ and ionomycin (500 $\mathrm{ng} \mathrm{ml}^{-1}$ ) using BD GolgiStop (BD Biosciences, Oxford, UK) for $3 \mathrm{~h}$ at $37^{\circ} \mathrm{C}$. Lung and BAL cells were incubated with anti-mouse CD16/CD32 (FC Block, BD Biosciences) before staining for cell surface markers: CD3e (clone 500A2), CD4 (clone RM4-5), CD8a (clone 53-6.7), NK1.1 (clone PK136), NKp46 (clone 29A1.4), and CD69 (clone H1.2F3) (all BD Biosciences). Cells were washed and stained with Live/Dead fixable dead cell stain kit (Invitrogen, Paisley, UK), followed by incubation with BD Fix/Perm solution (BD Biosciences). For ICS, cells were stained for IFN- $\gamma$ (clone XMG1.2, BD Biosciences) and granzyme B (clone GB12, Invitrogen) in $\mathrm{BD}$ PermWash ${ }^{\mathrm{TM}}$ (BD Biosciences). Data were acquired using a $\mathrm{BD}$ LSR II digital flow cytometer (BD Biosciences) and BD FACS Diva software (Oxford, UK). Analysis was performed using FlowJo 9.3.1.2 software (Oxford, UK).

Statistical analyses. For human studies, IL-15 data are presented as mean ( \pm s.e.m.). Baseline and infection peak data were comparatively analyzed with the Mann-Whitney test. Correlations between data sets were examined using Spearman's rank correlation coefficient for nonparametric data. Differences were considered significant for all statistical tests at $P<0.05$. All reported $P$-values are two sided. Animal experiments involved 4-7 mice per group in up to three independent experiments. Data were analyzed using two-way ANOVA and Bonferroni's multiple comparison test. All statistics were calculated using Prism 4 software (Graphpad, La Jolla, CA), with $P<0.05$ taken as significant.

Study approval. The human infection studies were approved by St Mary's National Health Service Trust Research Ethics committee. All subjects gave written informed consent. All animal work was completed in accordance with UK Home Office guidelines following approval via the ethical approval process (UK project licence PPL 70/7234).

SUPPLEMENTARY MATERIAL is linked to the online version of the paper at http://www.nature.com/mi

\section{ACKNOWLEDGMENTS}

We thank Eric Butz (Amgen, Seattle, USA) for providing the IL-15neutralizing antibody and Cecilia Johansson (Imperial College London, UK) for providing IFNAR1 ${ }^{-1-}$ mice. This work was supported by a Chair from Asthma UK (CH11SJ), MRC Centre Grant G1000758, ERC FP7 Advanced grant 233015, Predicta FP7 Collaborative Project grant 260895 and the Wellcome Trust sponsored Centre for Respiratory Infection (CRI).

\section{DISCLOSURE}

The authors declare no conflict of interest.

(c) 2014 Society for Mucosal Immunology

\section{REFERENCES}

1. Gerna, G. et al. Correlation of rhinovirus load in the respiratory tract and clinical symptoms in hospitalized immunocompetent and immunocompromised patients. J. Med. Virol. 81, 1498-1507 (2009).

2. Papadopoulos, N.G. et al. Rhinoviruses infect the lower airways. J. Infect. Dis. 181, 1875-1884 (2000).

3. Johnston, N.W. The similarities and differences of epidemic cycles of chronic obstructive pulmonary disease and asthma exacerbations. Proc. Am. Thorac. Soc. 4, 591-596 (2007).

4. Choi, S.H. et al. Viral infection in patients with severe pneumonia requiring intensive care unit admission. Am. J. Respir. Crit. Care Med. 186, 325-332 (2012).

5. Bertino, J.S. Cost burden of viral respiratory infections: issues for formulary decision makers. Am. J. Med. 112, 42-49 (2002).

6. Spurrell, J.C., Wiehler, S, Zaheer, R.S., Sanders, S.P. \& Proud, D. Human airway epithelial cells produce Ip-10 (Cxcl10) in Vitro and in vivo upon rhinovirus infection. Am. J. Physiol. Lung Cell Mol. Physiol. 289, 85-95 (2005).

7. Fraenkel, D.J. et al. Lower airways inflammation during rhinovirus colds in normal and in asthmatic subjects. Am. J. Respir. Crit. Care Med. 151, 879-886 (1995).

8. Levandowski, R.A., Ou, D.W. \& Jackson, G.G. Acute-phase decrease of T lymphocyte subsets in rhinovirus infection. J. Infect. Dis. 153, 743-748 (1986).

9. Bartlett, N.W. et al. Mouse models of rhinovirus-induced disease and exacerbation of allergic airway inflammation. Nat. Med. 14, 199-204 (2008).

10. Bartlett, N.W. et al. Defining critical roles for NF-kappaB p65 and type I interferon in innate immunity to rhinovirus. EMBO. Mol. Med. 4, 1244-1260 (2012).

11. Mattei, F, Schiavoni, G, Belardelli, F \& Tough, D.F. IL-15 is expressed by dendritic cells in response to type I IFN, double-stranded RNA, or lipopolysaccharide and promotes dendritic cell activation. J. Immunol. 167, 1179-1187 (2001).

12. Hansen, M.L. et al. IFN-alpha primes T- and NK-cells for IL-15-mediated signaling and cytotoxicity. Mol. Immunol. 48, 2087-2093 (2011).

13. Rochman, Y, Spolski, $R$ \& Leonard, W.J. New insights into the regulation of $\mathrm{T}$ cells by gamma(c) family cytokines. Nat. Rev. Immunol. 9, 480-490 (2009).

14. Giri, J.G. et al. Utilization of the beta and gamma chains of the IL-2 receptor by the novel cytokine IL-15. EMBO J. 13, 2822-2830 (1994).

15. Giri, J.G. et al. Identification and cloning of a novel IL-15 binding protein that is structurally related to the alpha chain of the IL-2 receptor. EMBO J. 14, 3654-3663 (1995).

16. Stonier, S.W. \& Schluns, K.S. Trans-presentation: a novel mechanism regulating $\mathrm{IL}-15$ delivery and responses. Immunol. Lett. 127, 85-92 (2010).

17. McGill, J, Van Rooijen, N \& Legge, K.L. IL-15 trans-presentation by pulmonary dendritic cells promotes effector CD8 T cell survival during influenza virus infection. J. Exp. Med. 207, 521-534 (2010).

18. Leavy, O. Maturation and function of NK cells. Nat. Rev. Immunol. 12, 150 (2012).

19. Biron, C.A., Nguyen, K.B., Pien, G.C., Cousens, L.P. \& Salazar-Mather, T.P. Natural killer cells in antiviral defense: function and regulation by innate cytokines. Ann. Rev. Immunol. 17, 189-220 (1999). 
20. Trinchieri, G \& Santoli, D. Anti-viral activity induced by culturing lymphocytes with tumor-derived or virus-transformed cells. Enhancement of human natural killer cell activity by interferon and antagonistic inhibition of susceptibility of target cells to lysis. J. Exp. Med. 147, 1314-1333 (1978).

21. Lee CkFau - Rao, D.T. et al. Distinct requirements for IFNs and STAT1 in NK cell function. J. Immunol. 165, 3571-3577 (2000).

22. Nguyen, K.B. et al. Coordinated and distinct roles for IFN-alpha beta, IL-12, and IL-15 regulation of NK cell responses to viral infection. J. Immunol. 169, 4279-4287 (2002).

23. Kennedy, M.K. etal. Reversible defects in natural killer and memory CD8Tcell lineages in interleukin 15-deficient mice. J. Exp. Med. 191, 771-780 (2000).

24. Lodolce, J.P. et al. IL-15 receptor maintains lymphoid homeostasis by supporting lymphocyte homing and proliferation. Immunity 9, 669-676 (1998).

25. Vankayalapati, R. et al. NK cells regulate CD8 + T cell effector function in response to an intracellular pathogen. J. Immunol. 172, 130-137 (2004).

26. Ge, M.Q. et al. NK cells regulate CD8 + T cell priming and dendritic cell migration during influenza A infection by IFN-gamma and perforindependent mechanisms. J. Immunol. 189, 2099-2109 (2012).

27. Wark, P.A. et al. Asthmatic bronchial epithelial cells have a deficient innate immune response to infection with rhinovirus. J. Exp. Med. 201, 937-947 (2005).

28. Mallia, P. et al. Experimental rhinovirus infection as a human model of chronic obstructive pulmonary disease exacerbation. Am. J. Respir. Crit. Care Med. 183, 734-742 (2011).

29. Laza-Stanca, V. et al. The role of IL-15 deficiency in the pathogenesis of virus-induced asthma exacerbations. PLoS Pathog. 7, e1002114 (2011)

30. Message, S.D. et al. Rhinovirus-induced lower respiratory illness is increased in asthma and related to virus load and Th1/2 cytokine and IL-10 production. Proc. Natl. Acad. Sci. USA 105, 13562-13567 (2008).

31. Newcomb, D.C. et al. Human rhinovirus 1B exposure induces phosphatidylinositol 3-kinase-dependent airway inflammation in mice. Am. J. Respir. Crit. Care Med. 177, 1111-1121 (2008).

32. Papadopoulos, N.G., Sanderson, G, Hunter, J \& Johnston, S.L. Rhinoviruses replicate effectively at lower airway temperatures. J. Med. Virol. 58, 100-104 (1999).

33. Lambrecht, B.N. \& Hammad, H. Lung dendritic cells in respiratory viral infection and asthma: from protection to immunopathology. Ann. Rev. Immunol. 30, 243-270 (2012).
34. Zeng, X. et al. Interferon-inducible protein 10 , but not monokine induced by gamma interferon, promotes protective type 1 immunity in murine Klebsiella pneumoniae pneumonia. Infect. Immun. 73, 8226-8236 (2005).

35. Sauty, A. et al. The Tcell-specific CXC chemokines IP-10, Mig, and I-TAC are expressed by activated human bronchial epithelial cells. J. Immunol. 162, 3549-3558 (1999).

36. Verbist, K.C., Cole, C.J., Field, M.B. \& Klonowski, K.D. A role for IL-15 in the migration of effector CD8 T cells to the lung airways following influenza infection. J. Immunol. 186, 174-182 (2011).

37. Verbist, K.C., Rose, D.L., Cole, C.J., Field, M.B. \& Klonowski, K.D. IL-15 participates in the respiratory innate immune response to influenza virus infection. PLOS ONE 7, e37539 (2012).

38. Liu, G. et al. IL-15 induces IFN-beta and iNOS gene expression, and antiviral activity of murine macrophage RAW 264.7 cells. Immunol. Lett. 91, 171-178 (2004).

39. Jinushi, M. et al. Autocrine/paracrine IL-15 that is required for type I IFN-mediated dendritic cell expression of MHC class I-related chain $A$ and $B$ is impaired in hepatitis $C$ virus infection. J. Immunol. 171, 5423-5429 (2003).

40. Sato, N, Patel, H.J., Waldmann, T.A. \& Tagaya, Y. The IL-15/IL-15Ralpha on cell surfaces enables sustained IL-15 activity and contributes to the long survival of CD8 memory T cells. Proc. Natl. Acad. Sci. USA 104, 588-593 (2007).

41. Dubois, S, Mariner, J, Waldmann, T.A. \& Tagaya, Y. IL-15Ralpha recycles and presents IL-15 In trans to neighboring cells. Immunity 17, 537-547 (2002).

42. Sugimoto, T. et al. Interleukin 18 acts on memory Thelper cells type 1 to induce airway inflammation and hyperresponsiveness in a naive host mouse. J. Exp. Med. 199, 535-545 (2004).

43. Chawes, B.L. et al. A novel method for assessing unchallenged levels of mediators in nasal epithelial lining fluid. J. Allergy. Clin. Immunol. 125, 1387-1389. e1383 (2010).

44. Nicholson, G.C. et al. The effects of an anti-IL-13 mAb on cytokine levels and nasal symptoms following nasal allergen challenge. J. Allergy. Clin. Immunol. 128, 800-807. e809 (2011).

45. Folsgaard, N.V. et al. Neonatal cytokine profile in the airway mucosal lining fluid is skewed by maternal atopy. Am. J. Respir. Crit. Care Med. 185, 275-280 (2012).

46. Varani, K. et al. Alteration of adenosine receptors in patients with chronic obstructive pulmonary disease. Am. J. Respir. Crit. Care Med. 173, 398-406 (2006) 